ARTICLE

\title{
Dpb4 promotes resection of DNA double-strand breaks and checkpoint activation by acting in two different protein complexes
}


Maria Pia Longhese (iD ${ }^{1 凶}$

Budding yeast Dpb4 (POLE3/CHRAC17 in mammals) is a highly conserved histone fold protein that is shared by two protein complexes: the chromatin remodeler ISW2/hCHRAC and the DNA polymerase $\varepsilon$ (Pol $\varepsilon$ ) holoenzyme. In Saccharomyces cerevisiae, Dpb4 forms histone-like dimers with DIs1 in the ISW2 complex and with Dpb3 in the Pol $\varepsilon$ complex. Here, we show that Dpb4 plays two functions in sensing and processing DNA double-strand breaks (DSBs). Dpb4 promotes histone removal and DSB resection by interacting with Dls1 to facilitate the association of the Isw2 ATPase to DSBs. Furthermore, it promotes checkpoint activation by interacting with Dpb3 to facilitate the association of the checkpoint protein Rad9 to DSBs. Persistence of both Isw2 and Rad9 at DSBs is enhanced by the A62S mutation that is located in the Dpb4 histone fold domain and increases Dpb4 association at DSBs. Thus, Dpb4 exerts two distinct functions at DSBs depending on its interactors.

\footnotetext{
${ }^{1}$ Dipartimento di Biotecnologie e Bioscienze, Università degli Studi di Milano-Bicocca, Milano, Italy. ${ }_{\text {email: mariapia.longhese@unimib.it }}$
} 
$\mathrm{D}$ NA double-strand breaks (DSBs) are harmful genomic lesions that threaten genome stability and cell survival. Eukaryotic cells use two main pathways for the repair of DSBs: non-homologous end-joining (NHEJ) and homologous recombination $(\mathrm{HR})^{1,2}$. HR requires that the $5^{\prime}$ strands at both DSB ends undergo nucleolytic degradation (resection), generating $3^{\prime}$-ended single-stranded DNA (ssDNA) tails that can invade the undamaged homologous DNA template ${ }^{3}$. DSB resection is initiated by the binding to the DSB ends of the evolutionarily conserved Mre11-Rad50-Xrs2/NBS1 (MRX/N) complex ${ }^{4}$. The Sae2 protein (CtIP in mammals) activates a latent endonuclease activity of Mre11, which cleaves the $5^{\prime}$-terminated strands at both DNA ends ${ }^{5}$. The resulting nick generates an entry site for both Mre11, which degrades back toward the DSB end in a $3^{\prime}-5^{\prime}$ direction, and the long-range resection Exo1 and Dna2 nucleases, which catalyze extended resection in a $5^{\prime}-3^{\prime}$ direction away from the DSB ${ }^{6-13}$. The MRX complex is also necessary to recruit Exo1 and Dna2 to DSBs ${ }^{3}$.

Repair of DNA DSBs occurs within chromatin, raising the question of how DSBs can be detected, signaled, and repaired within this context. Different subfamilies of chromatinremodeling enzymes catalyze a broad range of chromatin modifications, which include sliding histone octamer across the DNA, changing the conformation of nucleosomal DNA, or the composition of the histone octamer ${ }^{14}$. Eukaryotes have four subfamilies of chromatin-remodeling factors, namely SWI/SNF, ISWI, CHD, and INO80/SWR. In yeast, the RSC and the SWI/ SNF complexes, two members of the SWI/SNF chromatin remodeler family, promote MRX recruitment to DSBs and DSB resection by catalyzing eviction of nucleosomes adjacent to a $\mathrm{DSB}^{15-17}$. ssDNA generation at the DSB ends requires also the Ino80 complex that participates in the eviction of nucleosomes on either side of a DSB $18-21$.

Generation of DSBs elicits a cellular response, termed DNA damage checkpoint, that senses DNA damage and transduces this information to regulate several cellular processes, including cell cycle progression, DNA repair, and DNA replication ${ }^{22}$. Key players of the checkpoint cascade include the Saccharomyces cerevisiae protein kinases Mecl and Tel1, as well as their mammalian orthologs ATR and $\mathrm{ATM}^{23}$. Upon DNA damage recognition, these apical kinases activate the downstream effector kinases Rad53 (CHK2 in mammals) and Chk1. Rad53 and Chk1 activation require $\operatorname{Rad} 9$, which acts both as an adaptor between Mec1 and Rad53 and as a scaffold to promote Rad53 autophosphorylation and activation ${ }^{24-26}$.

In S. cerevisiae, Mec1 activation requires additional factors including the highly conserved Ddc1-Mec3-Rad17 (hereafter called 9-1-1) complex and the replication factor Dpb11 (TopBP1 in mammals ${ }^{27-29}$. The 9-1-1 complex, structurally related to the replication sliding clamp PCNA, recruits to DNA damaged sites Dpb11, which in turn interacts with the checkpoint protein Rad9 ${ }^{30-32}$. Dpb11-Rad9 interaction requires cyclin-dependent kinase (Cdk1)-mediated Rad9 phosphorylation on the S462 and T474 residues, which bind directly to the $\mathrm{N}$-terminal domain of Dpb1132.

Dpb11 is also part of the DNA polymerase $\varepsilon(\mathrm{Pol} \varepsilon$ ) holoenzyme, which is largely responsible for leading-strand synthesis during DNA replication. Pol $\varepsilon$ consists of Pol2, Dpb2, Dpb3 (POLE4 in mammals), and Dpb4 (POLE3/CHRAC17 in mammals) subunits ${ }^{33-35}$. Both Dpb3 and Dpb4 contain a histone fold domain, through which they interact to form a H2A-H2B-like complex that is not essential for cell viability in budding yeast $^{36,37}$. In both yeast and mammals, the Dpb3-Dpb4 complex binds $\mathrm{H} 3-\mathrm{H} 4$ tetramers and facilitates their transfer onto the leading strand during DNA replication through an intrinsic chaperone activity ${ }^{38,39}$. Interestingly, genetic studies reveal a role for $\mathrm{Dpb} 3$ and $\mathrm{Dpb} 4$ in maintaining the silenced state of chromatin ${ }^{40-42}$, suggesting that a defect in parental $\mathrm{H} 3-\mathrm{H} 4$ transfer in $d p b 3 \Delta$ and $d p b 4 \Delta$ cells might compromise epigenetic inheritance. The maintenance of heterochromatin silencing also involves the catalytic subunit of $\mathrm{Pol} \varepsilon^{40,41}$ and this function appears to be dependent upon Dpb3 and Dpb4, which bind double-stranded DNA (dsDNA) and increase Pol $\varepsilon$ association to $\mathrm{it}^{43}$.

Of note, in yeast, Drosophila melanogaster, and humans, Dpb4/ POLE3/CHRAC17 is also a component of the ISW2/hCHRAC chromatin-remodeling complex $40,44,45$, which catalyzes nucleosome sliding through the ATPase motor protein Isw2/hSNF2 $\mathrm{H}^{46}$. In the budding yeast ISW2 complex, Dpb4 interacts with the histone fold protein Dls1 that is considered a Dpb3 paralog 47 . In the mammalian ISW2 complex, the catalytic hSNF2H subunit has been implicated in the repair of DSBs by stimulating the association to them of the recombination protein $\mathrm{BRCA} 1^{48}$, while the noncatalytic ACF1 subunit directly interacts with the NHEJ protein complex KU70-KU80 and promotes its accumulation to $\mathrm{DSBs}^{49,50}$.

Here we show that the lack of $S$. cerevisiae Dpb4 reduces both histone removal from the DSB ends and MRX accumulation at DSBs. The poor MRX retention in $d p b 4 \Delta$ cells leads to a defective DSB resection. Furthermore, the lack of Dpb4 impairs activation of the checkpoint response by reducing Rad9 association to DSBs. Dpb4 promotes DSB resection and checkpoint activation by acting in two different protein complexes. In fact, Dpb4 interacts with Dls1 to promote Isw2 association to DSBs, histone removal, and DSB resection, while it interacts with Dpb3 to promote Rad9 association to DSBs and checkpoint activation.

\section{Results}

The $d p b 4-A 62 S$ allele exacerbates the sensitivity to camptothecin of tel1 $\triangle$ and $\operatorname{sae} 2 \Delta$ cells more severely than DPB4 deletion. Cells lacking Tel1 are specifically sensitive to camptothecin $(\mathrm{CPT})^{51}$, which stabilizes DNA topoisomerase I cleavage complexes, yielding to replication-dependent $\mathrm{DSBs}^{52}$. We have previously searched for extragenic mutations that exacerbated the CPT hypersensitivity of tell cells $^{53}$. Genome sequencing and genetic analysis revealed that one of the mutations responsible for the increased CPT sensitivity of tell $\Delta$ cells was a single nucleotide change in the DPB4 gene that caused the replacement of Ala62 with Ser. The synthetic cytotoxicity caused by the $d p b 4-A 62 S$ allele turned out to be not specific for tell $\Delta$ cells (Fig. 1a), as the same mutation also exacerbated the sensitivity to CPT of sae2 $\Delta$ cells (Fig. 1b).

To understand whether the $d p b 4-A 62 S$ mutation exacerbates the DNA damage sensitivity of tell $\Delta$ and sae2 $\Delta$ cells by disrupting Dpb4 function, we analyzed the effect of DPB4 deletion. $d p b 4 \Delta$ tell $\Delta$ and $d p b 4 \Delta$ sae $2 \Delta$ cells were less sensitive to CPT than $d p b 4-A 62 S$ tell $\Delta$ and $d p b 4-A 62 S$ sae2 $\Delta$ cells, respectively (Fig. 1a, b), suggesting that the synthetic effect caused by the dpb4-A62S allele is not due to loss of Dpb4 function. Although the DPB4 deletion increased less severely the DNA damage sensitivity of tell $\Delta$ and sae2 $\Delta$ cells compared to $d p b 4$ A62S, $d p b 4 \Delta$ cells were more sensitive than $d p b 4-A 62 S$ cells not only to a high CPT dose, but also to phleomycin and methyl methanesulfonate (MMS) (Fig. 1c). Altogether, these data suggest that the $d p b 4-A 62 S$ allele increases the DNA damage sensitivity of tell $1 \Delta$ and sae2 $\Delta$ cells by altering specific Dpb4 function(s).

Dpb4 promotes DSB resection and MRX association at DSBs. To assess the possible role of Dpb4 in DSB repair, we directly monitored ssDNA generation at the DSB ends by deleting DPB4 or introducing the $d p b 4-A 62 S$ allele in a haploid strain carrying 



Fig. 1 The dpb4-A62S mutation exacerbates the CPT sensitivity of tel1s and sae2s cells. a-c Exponentially growing cell cultures with the indicated genotypes were serially diluted (1:10) and each dilution was spotted out onto YEPD plates with or without camptothecin (CPT), phleomycin (phleo), or methyl methanesulfonate (MMS) at the indicated concentrations.

the $H O$ gene under the control of a galactose-inducible promoter. In this strain, production of the $\mathrm{HO}$ endonuclease by galactose addition leads to the generation at the MAT locus of a single DSB that cannot be repaired by HR due to the lack of the homologous donor loci $H M L$ and $H M R^{54}$. Cells exponentially growing in raffinose were transferred to galactose to induce $\mathrm{HO}$ expression and genomic DNA was analyzed at different time points after $\mathrm{HO}$ induction. Because ssDNA is resistant to cleavage by restriction enzymes, progressively longer restriction fragments terminating at the broken end are generated as $5^{\prime}-3^{\prime}$ nucleolytic degradation uncovers one after another SspI site (Supplementary Fig. 1). The progression of resection can be monitored by following the kinetics of appearance of these longer restriction fragments after denaturing gel electrophoresis and Southern blot analysis with a ssRNA probe that anneals to the unresected strand at one side of the DSB. The intensity of each resection band to the total amount of DSB products is used to measure the kinetics of resection. As previously observed ${ }^{54,55}$, the resection products persisted throughout the experiment, suggesting that resection initiates asynchronously after HO-catalyzed DSB formation. The appearance of the ssDNA intermediates at the HO-induced DSB was less efficient in both $d p b 4 \Delta$ and $d p b 4-A 62 S$ cells compared to wildtype cells, with $d p b 4 \Delta$ cells showing the strongest resection defect (Fig. 2a, b).

The MRX complex binds rapidly to DSBs, where it initiates DSB resection ${ }^{23}$. Thus, we used chromatin immunoprecipitation (ChIP) and quantitative real-time PCR (qPCR) to monitor Mre11 recruitment near the HO-induced DSB in wild-type, $d p b 4 \Delta$ and dpb4-A62S cells expressing fully functional Myc-tagged Mre11 (Supplementary Fig. 2a). As resection of the DSB ends has the potential to cause a $50 \%$ decrease of input DNA, the ChIP signals were normalized not only to the efficiency of DSB induction, but also to the corresponding input for each time point. Mre11 association to the HO-induced DSB was lower in $d p b 4 \Delta$ and $d p b 4-A 62 S$ cells than in wild-type cells (Fig. $2 c$ ), with $d p b 4 \Delta$ cells again showing the strongest reduction. This decreased Mre11 recruitment was not due to lower Mre11 protein levels, as similar Mre11 amounts could be detected in protein extracts from wildtype, $d p b 4 \Delta$, and $d p b 4-A 62 S$ cells (Fig. $2 \mathrm{~d}$ ). The reduction of Mre11 association at DSBs correlates with the severity of the DSB resection defect displayed by $d p b 4 \Delta$ and $d p b 4-A 62 S$ cells, suggesting that the decreased Mre11 persistence at DSBs can account for the resection defect displayed by these mutants.

Dpb4 promotes histone removal near DSBs. DSB repair occurs within a chromatin context, in which DNA is packaged into nucleosomes. The density of nucleosome packaging has the potential to influence DSB repair and is regulated by ATPdependent chromatin remodelers, which use the energy derived from ATP hydrolysis to evict, assemble, reposition or exchange histones throughout the genome ${ }^{46}$. Chromatin immunoprecipitation experiments indicate that nucleosomes are removed around a DSB in both yeast and mammalian cells, supporting the hypothesis that nucleosomes represent barriers to nuclease activity $15-21,56,57$.

Dpb4 is part of the chromatin-remodeling ISW2/hCHRAC complex $40,44,45$, which catalyzes nucleosome sliding ${ }^{58-60}$. Thus, we asked whether the poor Mre11 association and the resection defect displayed by $d p b 4 \Delta$ and $d p b 4-A 62 S$ cells are due to nucleosome retention at the DSB ends. We used ChIP analysis and qPCR to evaluate histone $\mathrm{H} 2 \mathrm{~A}$ and $\mathrm{H} 3$ occupancy centromere-proximal to the irreparable HO-induced DSB at the MAT locus. To exclude possible effects of DNA replication on histone association to DNA, HO expression was induced by galactose addition to G2-arrested cells that were kept arrested in G2 with nocodazole. As expected, $\mathrm{H} 2 \mathrm{~A}$ and $\mathrm{H} 3$ signals near the HO-induced DSB decreased in wild-type cells, while they remained high in both $d p b 4 \Delta$ and $d p b 4-A 62 S$ cells, with $d p b 4 \Delta$ cells showing the strongest removal defect (Fig. 2e). Taken together, these findings indicate that $\mathrm{Dpb} 4$ is required for nucleosome removal at DSBs, suggesting that the lack of this function can account for both the poor MRX association at DSBs and the delay of DSB resection of $d p b 4 \Delta$ and $d p b 4-A 62 S$ cells.

Dpb4 promotes checkpoint activation in response to DSBs. The lack of Dpb4 impairs DSB resection, Mre11 association at DSBs, and histone removal more severely than the presence of the Dpb4-A62S mutant variant (Fig. 2). However, Dpb4-A62S exacerbates the DNA damage sensitivity of both tell $\triangle$ and sae $2 \Delta$ cells more severely than DPB4 deletion (Fig. 1a, b), suggesting that the synthetic effects caused by Dpb4-A62S are due to 
a
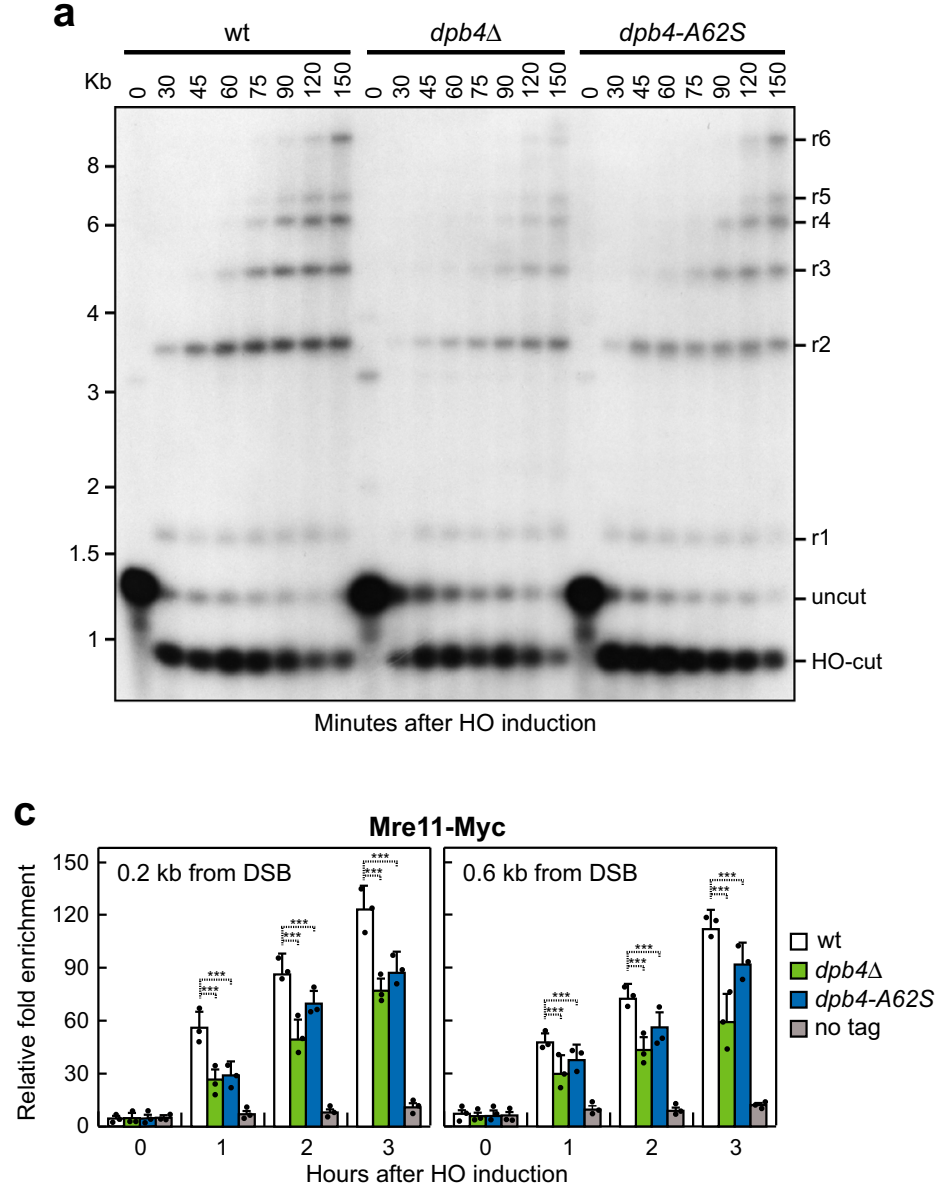

b


e


$\square d p b 4-A 62 S$

Fig. 2 dpb4 $\Delta$ and dpb4-A62S alleles reduce DSB resection, MRX association at DSBs, and histone removal from the DSB ends. a DSB resection. YEPR exponentially growing cell cultures of JKM139 derivative strains, carrying the HO cut site at the MAT locus, were transferred to YEPRG at time zero. Sspldigested genomic DNA was hybridized with a single-stranded MAT probe that anneals with the unresected strand. $5^{\prime}-3^{\prime}$ resection produces Sspl fragments ( $r$ through $r 6$ ) detected by the probe. $\mathbf{b}$ Densitometric analysis of the resection products. The mean values of three independent experiments as in $\mathbf{a}$ are represented with error bars denoting standard deviation (s.d.). c Exponentially growing YEPR cell cultures of JKM139 derivative strains were transferred to YEPRG to induce HO. Relative fold enrichment of Mre11-Myc at the HO-induced DSB was evaluated after ChIP with anti-Myc antibody and qPCR. The mean values of three independent experiments are represented with error bars denoting s.d. ${ }^{\star \star \star} p<0.005$ (unpaired two-tailed Student's $t$-test). $\mathbf{d}$ Western blot with anti-Myc antibodies of protein extracts from exponentially growing cells. This experiment was performed independently three times with similar results. e $\mathrm{HO}$ expression was induced at time zero by galactose addition to $\mathrm{G} 2$-arrested cells that were kept arrested in $\mathrm{G} 2$ by nocodazole throughout the experiment. Relative fold enrichment of $\mathrm{H} 2 \mathrm{~A}$ or $\mathrm{H} 3$ at the $\mathrm{HO}$-induced DSB was evaluated after ChIP with anti-H2A or anti-H3 antibody and qPCR analysis. The mean values of three independent experiments are represented with error bars denoting s.d. See source data file for statistical analysis. 


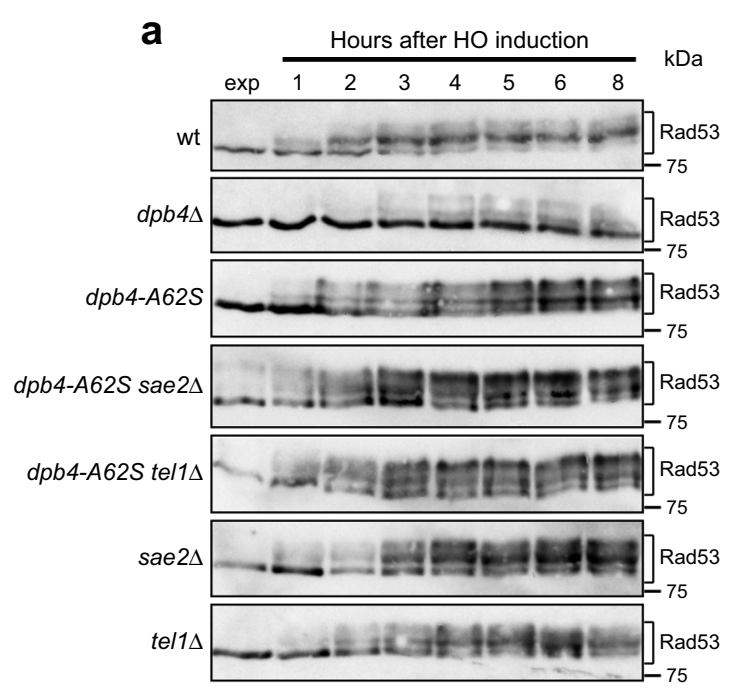

C



b


Fig. 3 Opposite effect of $\boldsymbol{d p b 4 \Delta}$ and $\boldsymbol{d p b 4 - A 6 2 S}$ on checkpoint activation and Rad9 association at DSBs. a YEPR exponentially growing cell cultures of JKM139 derivative strains were transferred to YEPRG at time zero. Western blot analysis with anti-Rad53 antibodies of protein extracts from samples taken at the indicated times after $\mathrm{HO}$ induction. The experiment was performed independently two times with similar results. b Phleomycin (10 $\mu \mathrm{g} / \mathrm{mL})$ was added to exponentially growing cells followed by western blot analysis with anti-Rad53 antibodies. The experiment was performed independently four times with similar results. c Exponentially growing YEPR cell cultures of JKM139 derivative strains were transferred to YEPRG to induce HO expression. Relative fold enrichment of Rad9-HA at the HO-induced DSB was evaluated after ChIP with anti-HA antibody and qPCR. The mean values of three independent experiments are represented with error bars denoting s.d. ${ }^{\star \star \star} p<0.005$ (unpaired two-tailed Student's t-test). d Western blot with anti-HA antibodies of protein extracts from exponentially growing cells. The experiment was performed independently three times with similar results.

changes of Dpb4 function in cellular processes other than DSB resection.

DSB formation leads to the activation of a checkpoint response that depends primarily on $\mathrm{Mec}$, which promotes activation of the Rad53 effector kinase ${ }^{61}$. Rad9 links the signal transduction from Mec1 to Rad53 by acting as a scaffold to allow Rad53 intermolecular autophosphorylation and activation $24-26$. We measured checkpoint activation in $d p b 4 \Delta$ and $d p b 4-A 62 S$ cells after HO-induced DSB formation or phleomycin treatment, by following Rad53 phosphorylation that is required for activation of Rad53 as a kinase and is detectable as a decrease of its electrophoretic mobility. When $\mathrm{HO}$ was induced by galactose addition to exponentially growing cells, the amount of slowly migrating phosphorylated Rad53 was much lower in $d p b 4 \Delta$ cells than in wild type (Fig. 3a). Similar results were obtained also when exponentially growing cells were treated with the radiomimetic drug phleomycin (Fig. 3b), indicating that Dpb4 is required to activate a checkpoint in response to DSBs. By contrast, the amount of the slowest migrating Rad53 form was slightly higher in $d p b 4-A 62 S$ cells than in wild-type cells and further increased in $d p b 4-A 62 S$ tell $\Delta$ and $d p b 4-A 62 S$ sae $2 \Delta$ cells compared to $d p b 4-A 62 S$, tell $\Delta$, and sae2 $\Delta$ cells both after $\mathrm{HO}$ induction (Fig. 3a) and phleomycin addition (Fig. 3b). Thus, the lack of Dpb4 reduces Rad53 activation in response to DSBs, whereas the Dpb4-A62S mutant variant enhances it.

As Dpb4 was shown to facilitate the association of the checkpoint protein Rad9 with telomeres by an unknown mechanism ${ }^{62}$, we analyzed Rad9 association at the HO-induced DSB by ChIP analysis and qPCR in cells expressing fully functional HA-tagged Rad9 (Supplementary Fig. 2b). Rad9 association to the HO-induced DSB was decreased in $d p b 4 \Delta$ cells compared to wild type, while it was increased in $d p b 4-A 62 S$ cells (Fig. 3c), although similar Rad9 amounts could be detected in protein extracts prepared from wild-type, $d p b 4 \Delta$ and $d p b 4$ A62S cells (Fig. 3d). These findings indicate that Dpb4 promotes Rad9 association at DSBs and checkpoint activation, and that this Dpb4 checkpoint function is enhanced by the dpb4-A62S mutation that leads to an increased Rad9 persistence at DSBs.

The finding that the $d p b 4-A 62 S$ allele increases Rad53 activation raises the possibility that the severe DNA damage hypersensitivity of $d p b 4-A 62 S$ tell $\Delta$ and $d p b 4-A 62 S$ sae2 $\Delta$ cells compared to tel1 $\Delta$ and sae2 $\Delta$ cells might be due to the hyperactivation of the checkpoint response. If this were the case, either RAD9 deletion or expression of the kinase defective 

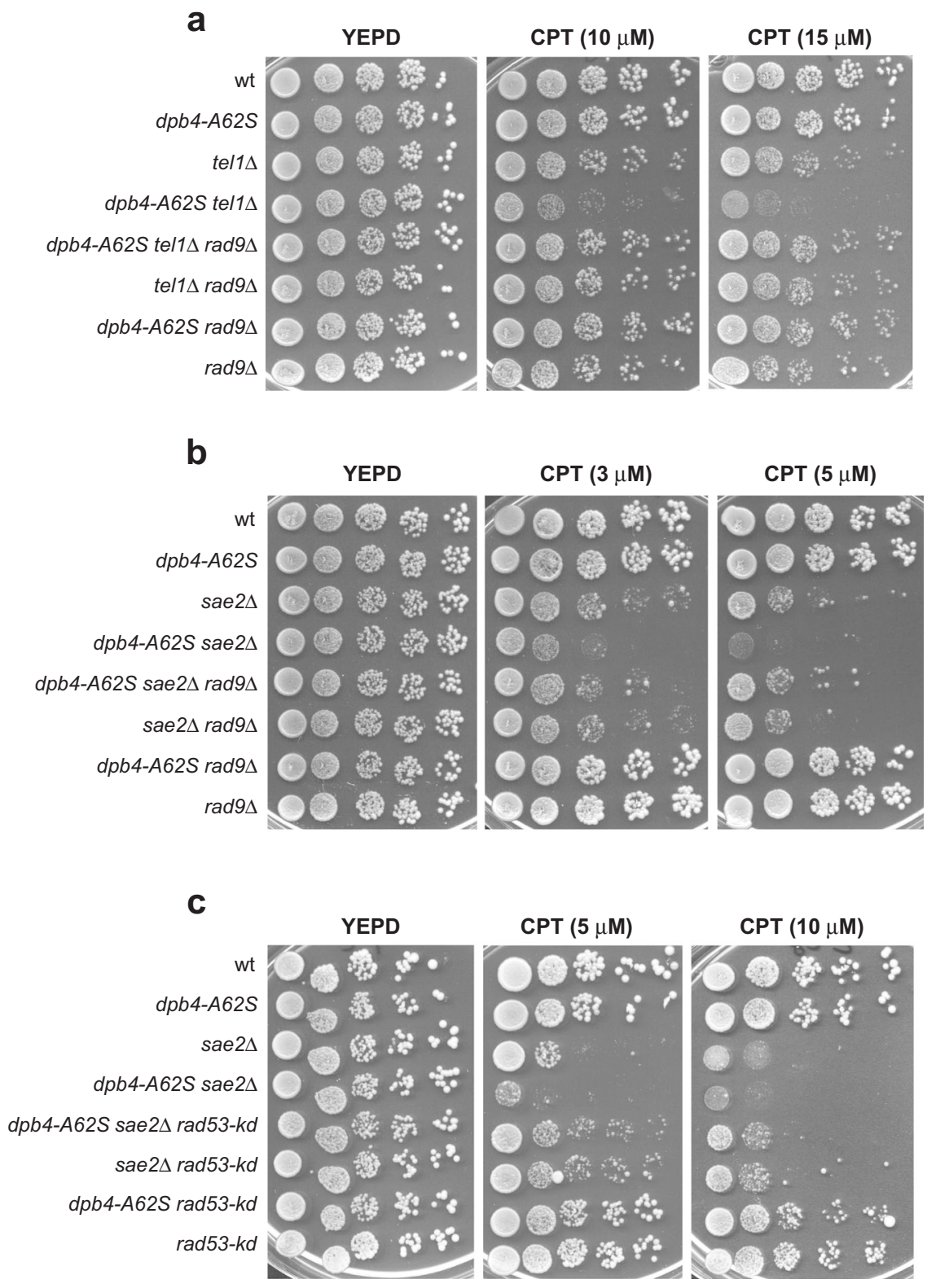

Fig. 4 Dpb4-A62S increases the DNA damage sensitivity of tel1s and sae2s cells in a Rad9- and Rad53-dependent manner. a-c Exponentially growing cultures with the indicated genotypes were serially diluted (1:10) and each dilution was spotted out onto YEPD plates with or without CPT.

rad53-K227A (rad53-kd) allele should decrease the DNA damage hypersensitivity of $d p b 4-A 62 S$ tel1 $\Delta$ and $d p b 4-A 62 S$ sae $2 \Delta$ cells. Indeed, $R A D 9$ deletion suppressed the CPT hypersensitivity of $d p b 4-A 62 S$ tell $\Delta$ cells, as $d p b 4-A 62 S$ tell $\Delta$ rad9 $\Delta$ cells were as sensitive to CPT as tell $\Delta$ rad9 9 cells (Fig. 4a). Furthermore, $R A D 9$ deletion was epistatic to $d p b 4-A 62 S$ with respect to the CPT sensitivity of sae $2 \Delta$ cells. In fact, $d p b 4-A 62 S$ sae $2 \Delta$ rad $9 \Delta$ cells, which were less sensitive to DNA damaging agents than $d p b 4-A 62 S$ sae $2 \Delta$ cells, were as sensitive as sae $2 \Delta$ rad9D cells (Fig. 4b).

Unfortunately, due to the poor viability of rad53-kd tel1 $\Delta$ double mutant even in the absence of DNA damaging agents, we could not evaluate the effect of the rad53-kd allele on $d p b 4-A 62 S$ tell $\Delta$ cells. In any case, expression of rad53- $k d$, which partially suppressed the DNA damage sensitivity of sae $2 \Delta$ cells $^{63}$, was epistatic to $d p b 4-A 62 S$ with respect to the CPT sensitivity of $d p b 4-A 62 S$ sae $2 \Delta$ cells, as $d p b 4-A 62 S$ sae $2 \Delta$ rad53- $k d$ cells were as sensitive to CPT as sae2 $\Delta$ rad53- $k d$ cells (Fig. $4 \mathrm{c}$ ). Thus, Rad9 and Rad53 kinase activity are required for Dpb4-A62S to increase the
DNA damage sensitivity of tell $\Delta$ and sae $2 \Delta$ cells, suggesting that the enhanced checkpoint activation by Dpb4-A62S leads to DNA damage-induced lethality in the presence of unrepaired DNA lesions.

Dpb4 and Dot1 promote Rad9 association to DSBs by acting in the same pathway and independently of Dpb11 and $\gamma \mathrm{H} 2 \mathrm{~A}$. In both yeast and mammals, Rad9 association with chromatin involves at least three pathways. First, Rad9 is constitutively bound to chromatin even in the absence of DNA damage through an interaction with histone $\mathrm{H} 3$ methylated at Lys79 (H3-K79me), a modification that is catalyzed by the methyltransferase Dot1 ${ }^{64-69}$. Furthermore, phosphorylation of Ser462 and Thr474 Rad9 residues by Cdk1 leads to Rad9 interaction with Dpb11 $1^{32,70,}$ which is recruited to DSBs by the 9-1-1 complex ${ }^{29,71}$. Finally, DNA damage induces Rad9 binding to histone $\mathrm{H} 2 \mathrm{~A}$ that has been phosphorylated at Ser129 $(\gamma \mathrm{H} 2 \mathrm{~A})$ by the checkpoint kinases Mec1/ATR and Tel1/ATM ${ }^{55,72-74}$. 
a

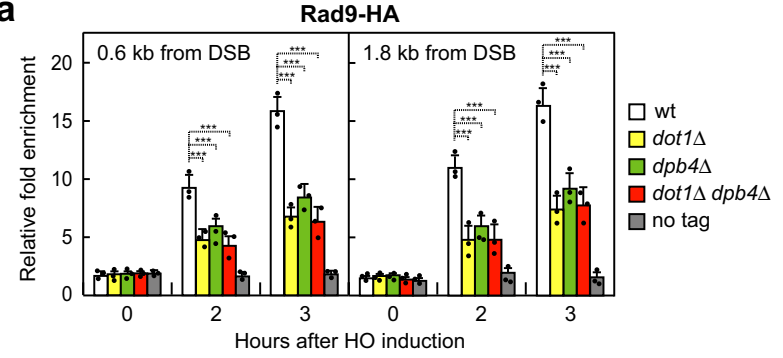

b

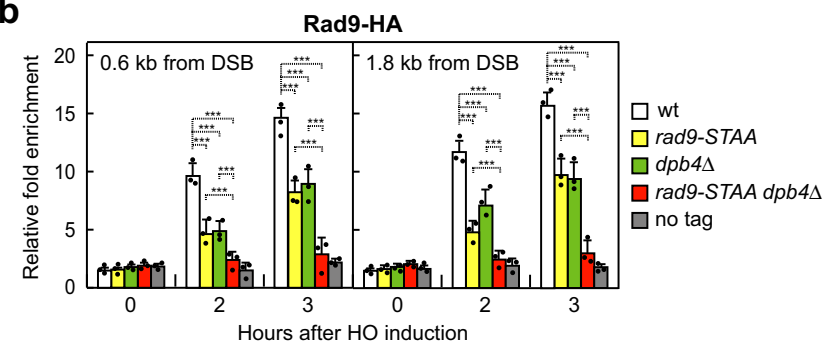

C



d



Fig. 5 Dpb4 promotes Rad9 association at DSBs independently of $\gamma \mathrm{H} 2 \mathrm{~A}$ and Dpb11-Rad9 interaction and by acting in the same pathway of Dot1. a-d Exponentially growing YEPR cell cultures of JKM139 derivative strains were transferred to YEPRG to induce $\mathrm{HO}$ expression. Relative fold enrichment of Rad9-HA (a-c) and Dpb4-HA (d) at the HO-induced DSB at the MAT locus was evaluated after ChIP with anti-HA antibody and qPCR. Strains carrying the hta1-S129A allele also contain the deletion of the HTA2 gene. The mean values of three independent experiments are represented with error bars denoting s.d. ${ }^{\star \star \star} p<0.005 ;{ }^{\star} p<0.05$ (unpaired two-tailed Student's t-test)

To investigate whether Dpb4 promotes Rad9 association to DSBs by acting in one of the above pathways, we analyzed the contribution of Dpb4 in supporting Rad9 association to DSBs in cells that were defective in Rad9 binding to either H3-K79me, $\gamma \mathrm{H} 2 \mathrm{~A}$, or Dpb11. As expected, the lack of Dot1, which abolishes H3-K79me generation ${ }^{64-66}$, decreased Rad9 association to the HO-induced DSB (Fig. 5a). A similar decrease of Rad9 persistence at DSBs could be detected upon expression of either the rad9-S462A, T474A (rad9-STAA) (Fig. 5b), or the hta1-S129A allele (Fig. 5c), which abolish Rad9-Dpb11 interaction and $\gamma \mathrm{H} 2 \mathrm{~A}$ generation, respectively. Interestingly, DPB4 deletion did not further decrease the amount of Rad9 bound to DSBs in $\operatorname{dot} 1 \Delta$ cells (Fig. 5a), indicating that Dpb4 and Dot1 promote Rad9 association at DSBs by controlling the same pathway. By contrast, Rad9 association at DSBs was markedly decreased in both rad9-


mutants compared to each single mutant, indicating that Dpb4 function in promoting $\operatorname{Rad} 9$ association at DSBs occurs independently of $\operatorname{Rad} 9-\gamma \mathrm{H} 2 \mathrm{~A}$ and Dpb11-Rad9 interactions. Consistent with this conclusion, when $\mathrm{HO}$ was induced in exponentially growing cells expressing fully functional Dpb4-HAtagged protein (Supplementary Fig. 2c), Dpb4 recruitment to the HO-induced DSB requires neither the 9-1-1 complex nor the interaction between 9-1-1 and Dpb11. In fact, the lack of Ddc1 or the presence of the $d d c 1-T 602 A$ allele, which specifically abrogates 9-1-1 binding to Dpb11 $1^{31}$, did not decrease Dpb4 association to the HO-induced DSB (Fig. 5d).

Different interactors support Dpb4 functions in DSB resection and checkpoint activation. The Dpb4 protein is shared by two highly conserved protein complexes: the chromatin-remodeling ISW2 $2^{40,44,45}$ and the Pol $\varepsilon$ complexes ${ }^{33-35}$. In both complexes, Dpb4 forms a dimer that resembles $\mathrm{H} 2 \mathrm{~A}-\mathrm{H} 2 \mathrm{~B}$ by interacting with two different histone fold proteins: Dls1 in the ISW2 complex and Dpb3 in the Pol $\varepsilon$ complex ${ }^{35,40,45}$.

Both Pol 2 and Dpb2 subunits of the Pol $\varepsilon$ complex are essential for cell viability. We, therefore, investigated the effects of deleting $D P B 3, D L S 1$, and the ATPase encoding gene ISW2 in order to assess the contribution of Pol $\varepsilon$ and ISW2 complexes in supporting Dpb4 functions in DSB resection and checkpoint activation. Deletion of ISW2 and DLS1, but not of DPB3, severely reduced removal of $\mathrm{H} 2 \mathrm{~A}$ (Fig. 6a) and $\mathrm{H} 3$ histones (Supplementary Fig. 3) from the HO-induced DSB. Furthermore, isw $2 \Delta$ and dls1 $\Delta$ cells showed decreased Mre11 association to the HOinduced DSB, whereas $d p b 3 \Delta$ cells did not (Fig. 6b). Consistent with the finding that Isw2 is the catalytic subunit, whereas both Dpb4 and Dls1 help nucleosome sliding by ISW2 ${ }^{59}$, isw $2 \Delta$ cells showed a more severe impairment of Mre11 association to the HO-induced DSB compared to both $d p b 4 \Delta$ and $d l s 1 \Delta$ cells (Fig. 6b). DPB4 deletion did not further decrease the amount of Mre11 bound at DSB in isw2 $\Delta$ cells (Fig. 6b), indicating that Dpb4 and Isw2 promote MRX association by acting in the same pathway. Finally, both $i s w 2 \Delta$ and $d l s 1 \Delta$ cells were defective in resection of the $\mathrm{HO}$-induced DSB compared to wild-type cells (Fig. 6c, d). Altogether, these findings indicate that Dpb4 promotes histone removal, MRX association to DSBs, and DSB resection by acting in the ISW2 complex.

It has been proposed that Dpb4 acts as an anchor point on DNA for Isw2 75 , prompting us to test whether the defect in histone removal in $d p b 4 \Delta$ cells is due to a decreased association of the Isw2 catalytic subunit to DSBs. The amount of Isw2 bound at the HO-induced DSB was markedly reduced in $d p b 4 \Delta$ cells (Fig. 6e), although similar Isw2 levels were present in both wildtype and $d p b 4 \Delta$ cell extracts (Fig. 6f), indicating that Dpb4 promotes Isw2 association to DSBs. By contrast, $d p b 4-A 62 S$ cells, which showed defective nucleosome eviction from DSBs (Fig. 2e), exhibited increased Isw2 persistence at the HO-induced DSB (Fig. 6e), suggesting that not only a decreased but also an increased Isw2 association at DSBs might impair histone removal. Consistent with this hypothesis, deletion of the negatively charged C terminus of the D. melanogaster Dpb4 ortholog enhances DNA binding but inhibits nucleosome sliding ${ }^{59}$.

In agreement with the conclusion that Dpb3 did not support Dpb4 function in removing histones and in promoting Mre11 association to DSBs (Fig. 6a, b), $d p b 3 \Delta$ cells were not defective in DSB resection (Fig. 7a and Supplementary Fig. 4). Instead, Dpb3, but not the ISW2 complex, supports the Dpb4 function in checkpoint activation. In fact, $d p b 3 \Delta$ cells, but not $i s w 2 \Delta$ cells, 
a
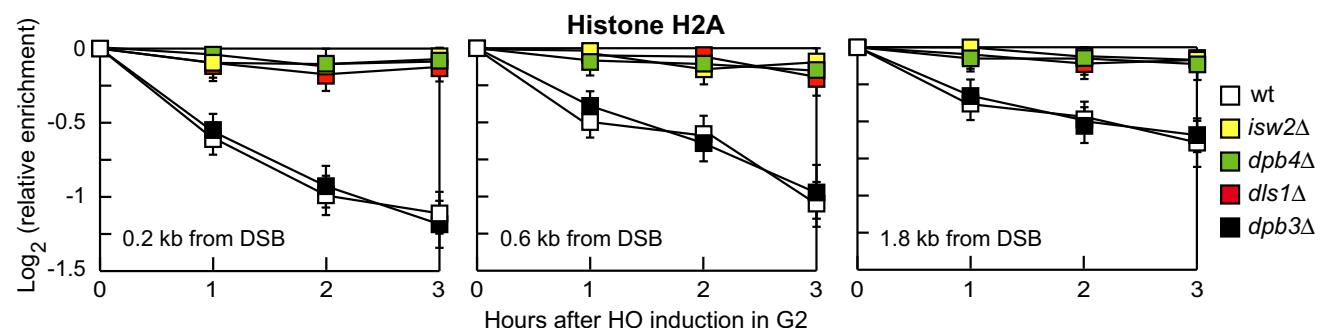

b

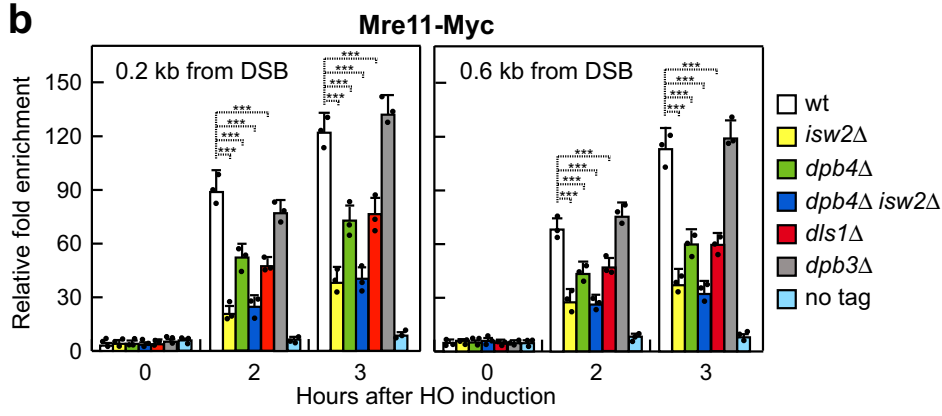

C

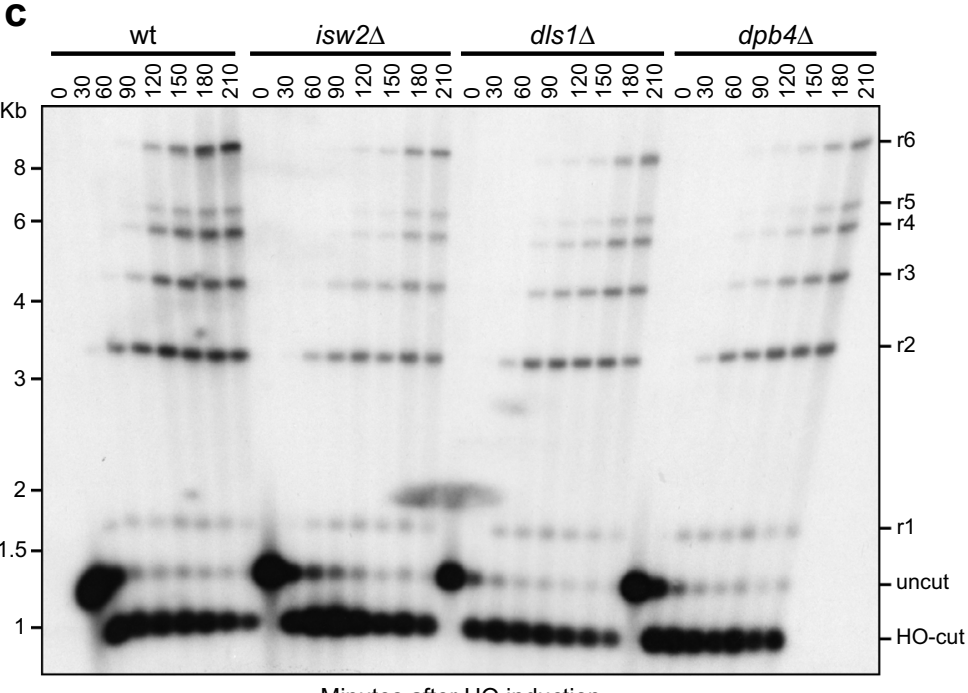

d
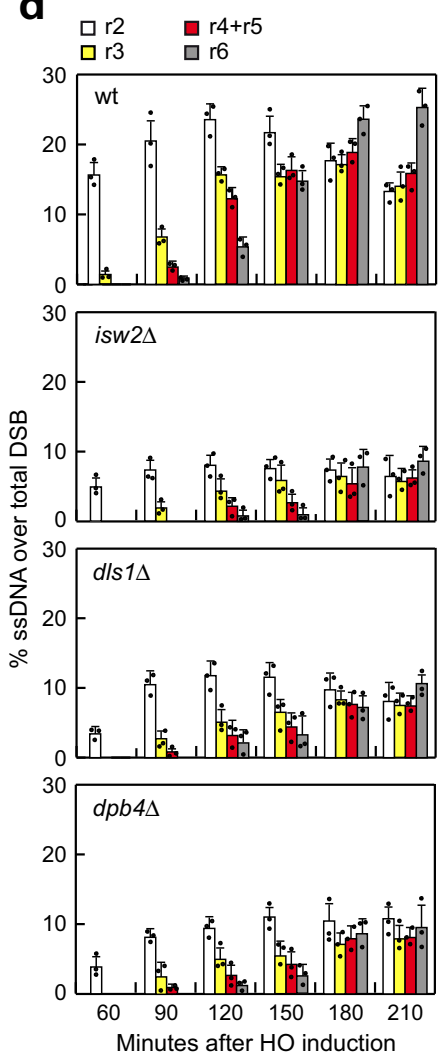

Minutes after $\mathrm{HO}$ induction

e

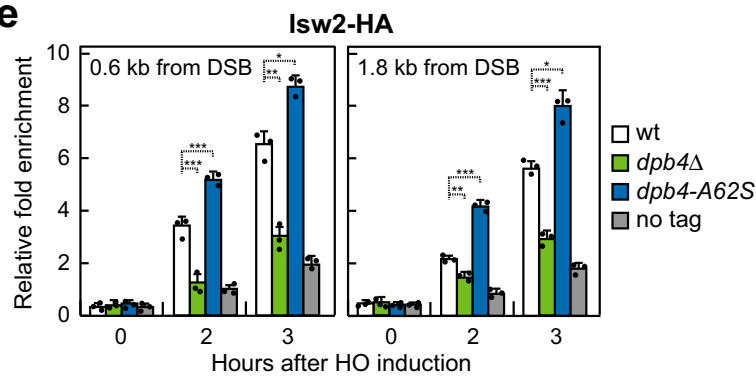

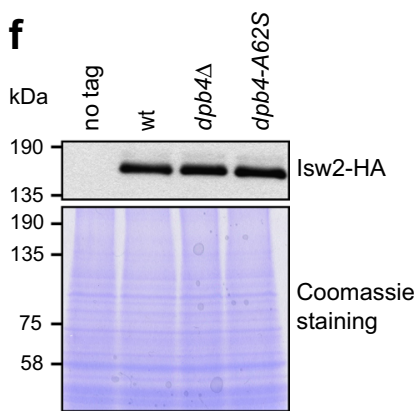

showed decreased Rad53 phosphorylation after $\mathrm{HO}$ induction (Fig. 7b) or phleomycin treatment (Fig. 7c). Similarly, $d p b 3 \Delta$ cells, but not isw2 $\Delta$ cells, showed reduced Rad9 association at the HOinduced DSB compared to wild-type cells (Fig. 7d). The lack of Dpb4 did not further decrease the amount of Rad9 bound at DSB in $d p b 3 \Delta$ cells, indicating that Dpb3 and Dpb4 act in the same pathway to promote Rad9 association to DSBs (Fig. 7d). Consistent with the finding that the ISW2 complex is not involved in checkpoint activation, Isw2 and Dls1 proteins are not required to increase the DNA damage sensitivity of $d p b 4-A 62 S$ tell $1 \Delta$ cells, as $d p b 4-A 62 S d l s 1 \Delta$ tell $\Delta$ and $d p b 4-A 62 S$ isw $2 \Delta$ tel1 $\Delta$ cells were as sensitive to CPT as $d p b 4-A 62 S$ tell $\Delta$ cells (Fig. 7e, f). Altogether, these findings indicate that Dpb4 acts in the ISW2 complex to promote MRX association at DSBs and DSB resection, whereas it acts with Dpb3 to promote checkpoint activation.

The Dpb3-Dpb4 heterodimer is part of the Pol $\varepsilon$ holoenzyme ${ }^{35}$, which was previously shown to promote checkpoint activation in response to DNA replication stress ${ }^{76-79}$. The Dpb3-Dpb4 complex was shown to enhance both the processivity of Pol $\varepsilon^{42,43,80}$ and the DNA binding activity of Pol2 ${ }^{41}$. The Pol $\varepsilon$ checkpoint function relies on the C-terminal domain of Pol2, which is essential for cell viability, making it difficult to assess 
Fig. 6 The lack of DIs1 and Isw2, but not of Dpb3, impairs histone removal, MRX association to DSBs, and DSB resection. a HO expression was induced at time zero by galactose addition to G2-arrested cells that were kept arrested in $\mathrm{G} 2$ by nocodazole. Relative fold enrichment of $\mathrm{H} 2 \mathrm{~A}$ at the HO-induced DSB was evaluated after ChIP with an anti-H2A antibody. The mean values of three independent experiments are represented with error bars denoting s.d. See source data file for statistical analysis. $\mathbf{b}$ Exponentially growing YEPR cell cultures were transferred to YEPRG to induce HO expression. Relative fold enrichment of Mre11-Myc at the HO-induced DSB was evaluated after ChIP with anti-Myc antibody and qPCR. The mean values of three independent experiments are represented with error bars denoting s.d. ${ }^{\star * \star} p<0.005$ (unpaired two-tailed Student's $t$-test). c DSB resection. YEPR exponentially growing cell cultures were transferred to YEPRG at time zero to induce HO production. Sspl-digested genomic DNA was analyzed as in Fig. 2a. d Densitometric analysis of the resection products. The mean values of three independent experiments as in (c) are represented with error bars denoting s.d. See source data file for statistical analysis that was performed using unpaired two-tailed Student's $t$-test. e Exponentially growing YEPR cell cultures of JKM139 derivative strains were transferred to YEPRG to induce $\mathrm{HO}$ expression. Relative fold enrichment of Isw2-HA at the HO-induced DSB was evaluated after ChIP with anti-HA antibody and qPCR. The mean values of three independent experiments are represented with error bars denoting s.d. ${ }^{\star \star \star} p<0.005 ;{ }^{\star \star} p<$ 0.01 ; ${ }^{\star} p<0.05$ (unpaired two-tailed Student's $t$-test). $\mathbf{f}$ Western blot with anti-HA antibodies of protein extracts from exponentially growing cells. The experiment was performed independently three times with similar results.

whether Dpb3-Dpb4 promotes Rad9 association to DSBs and checkpoint activation by acting within the Pol $\varepsilon$ complex. As the enhanced checkpoint activation caused by $\mathrm{Dpb} 4^{\mathrm{A} 62 \mathrm{~S}}$ is likely due to the increased Rad9 association to DSBs, if the Dpb4 checkpoint function involves the Pol $\varepsilon$ holoenzyme, Dpb4 $4^{\mathrm{A} 62 \mathrm{~S}}$ should cause an increased Pol2 persistence to DSBs. To exclude possible effects of DNA replication, HO expression was induced by galactose addition to G2-arrested cells that were kept arrested in G2 with nocodazole. Following $\mathrm{HO}$ induction, Pol2 was recruited to the HO-induced DSB (Fig. 7g). Furthermore, although wild-type, $d p b 4 \Delta$, and $d p b 4-A 62 S$ cells contained a similar amount of Pol2 (Fig. 7h), the A62S mutation increased Pol2 occupancy at the HO-induced DSB, whereas the lack of Dpb4 decreased it (Fig. 7g), suggesting that $\mathrm{Dpb} 4$ might act through Pol $\varepsilon$ to promote checkpoint activation in response to DSBs.

The A62S mutation favors the formation of high order Dpb4-Dpb3 and Dpb4-Dls1 complexes on DNA. Dpb4, Dpb3, and Dls1 contain a histone fold (helix-turn-helix-turn-helix) domain (Fig. 8a), through which they interact to form H2A-H2Blike Dpb3-Dpb4 and Dls1-Dpb4 heterodimers ${ }^{40,44,45,81}$. Sequence and structural analyses indicate that the A62 residue is localized on the $\alpha 2$ helix within the histone fold domain and interacts with I74 and I87 residues that are localized on the a3 helix of the histone fold domain of Dpb3 and Dls1, respectively (Fig. 8b).

The A62S mutation did not impair Dpb3-Dpb4 and Dls1-Dpb4 complex formation in vivo. In fact, when Dpb4-HA or $\mathrm{Dpb}^{\mathrm{A} 62 \mathrm{~S}_{-} \mathrm{HA}}$ was immunoprecipitated with anti-HA antibodies, a similar amount of Dpb3-Myc could be detected in the immunoprecipitates (Supplementary Fig. 5a). Similarly, when Dls1-HA was immunoprecipitated with anti-HA antibodies, similar amounts of Dpb4-Myc and Dpb4 ${ }^{\mathrm{A} 62 \mathrm{~S}}$-Myc could be detected in the immunoprecipitates (Supplementary Fig. 5b).

The lack of Dpb4 impairs the association to DSBs of both Isw2 and Pol2, whereas the A62S mutation increases it, prompting us to test whether the functions of Dpb4 in both histone eviction and checkpoint activation rely on its DNA binding activity that can be enhanced by the A62S mutation. When $\mathrm{HO}$ was induced by galactose addition to G2-arrested cells that were kept arrested in G2 with nocodazole to exclude the possible effect of DNA replication, $\mathrm{Dpb} 4$ was efficiently recruited close to the $\mathrm{HO}$ cut site (Fig. 8c). Although the A62S substitution did not affect Dpb4 protein level within cells (Fig. 8d) and the addition of the HA tag at the $\mathrm{Dpb} 4{ }^{\mathrm{A} 62 \mathrm{~S}} \mathrm{C}$ terminus did not alter the DNA damage sensitivity of $d p b 4-A 62 S$ cells (Supplementary Fig. 2c), the amount of Dpb4 ${ }^{\mathrm{A} 62 \mathrm{~S}}$ bound at the HO-induced DSB was higher than that of wild-type Dpb4 (Fig. 8c). This finding suggests that the A62S mutation increases the $\mathrm{Dpb} 4$ association to dsDNA.
To investigate whether the A62S mutation enhances Dpb4 occupancy at DSBs by increasing the DNA binding affinity of Dpb3-Dpb4 and/or Dls1-Dpb4 complexes, we expressed and purified Dpb3-Dpb4, Dpb3-Dpb4 ${ }^{\mathrm{A} 62 \mathrm{~S}}$, Dls1-Dpb4, and Dls1-Dpb4 ${ }^{\mathrm{A} 62 \mathrm{~S}}$ heterodimers as soluble protein complexes from Escherichia coli cells (Supplementary Fig. 6a, b). Circular dichroism (CD) spectra of Dpb3-Dpb4 and Dls1-Dpb4 present two minima at $208 \mathrm{~nm}$ and $222 \mathrm{~nm}$, which are typical of $\alpha$-helix structures (Supplementary Fig. 6c, d). The CD spectra of $\mathrm{Dpb} 3-\mathrm{Dpb} 4^{\mathrm{A} 62 \mathrm{~S}}$ and Dls1-Dpb4 ${ }^{\mathrm{A} 62 \mathrm{~S}}$ are similar to those of the wild-type complexes, indicating that the A62S substitution does not affect the protein secondary structure (Supplementary Fig. $6 \mathrm{c}, \mathrm{d}$ ). The thermal stability of the chimeric heterodimers was investigated by CD spectroscopy at a fixed wavelength (208 $\mathrm{nm}$ ) in the $25-90^{\circ} \mathrm{C}$ temperature range. The unfolding transition midpoint temperatures $\left(T_{\mathrm{m}}\right)$ of Dpb3-Dpb4 and Dls1-Dpb4 are $61.57 \pm 0.39$ and $57.05 \pm 0.31^{\circ} \mathrm{C}$, respectively, whereas the $\mathrm{A} 62 \mathrm{~S}$ mutation decreases the $T_{\mathrm{m}}$ of Dpb3-Dpb4 and Dls1-Dpb4 complexes of $\sim 3$ and $2{ }^{\circ} \mathrm{C}$, respectively (Supplementary Fig. 6e, f), suggesting that the $\mathrm{A} 62 \mathrm{~S}$ mutation induces slight conformational changes in both complexes.

To test the DNA binding properties of these protein complexes, increasing concentrations of purified Dpb3-Dpb4, Dpb3-Dpb4 ${ }^{\mathrm{A} 62 \mathrm{~S}}$, Dls1-Dpb4, and Dls1-Dpb4 ${ }^{\mathrm{A} 62 \mathrm{~S}}$ protein complexes were incubated with a fixed amount of a 61-mer dsDNA substrate to test their ability to bind DNA in a gel electrophoretic mobility shift assay (EMSA). As previously reported ${ }^{41}$, the addition of wild-type Dpb3-Dpb4 or Dls1-Dpb4 complexes was capable of shifting the dsDNA oligomer into a distinct slower migrating band (Fig. 8e, f), indicating that both complexes can bind dsDNA. Notably, both Dpb3-Dpb4 ${ }^{\mathrm{A} 62 \mathrm{~S}}$ and Dls1-Dpb4 ${ }^{\mathrm{A} 62 \mathrm{~S}}$ were capable of generating a similar slower migrating band although less efficiently compared to the corresponding wild-type complexes (Fig. 8e, f). However, they both showed the appearance of a second slower migrating band (Fig. 8e, f), suggesting that the A62S amino acid substitution favors a transition to higher-order Dpb3-Dpb4-DNA and Dls1-Dpb4-DNA complexes that can explain the increased amount of $\mathrm{Dpb} 4$ bound to DSBs detected by ChIP.

\section{Discussion}

Our data show that the conserved histone fold protein Dpb4 is involved in at least two aspects of the cellular response to DSBs: (i) it promotes MRX association to DSBs, thus allowing DSB resection; (ii) it promotes $\operatorname{Rad} 9$ association to DSBs, thus allowing checkpoint activation. We found that Dpb4 is required to remove histones around a DSB. As the presence of nucleosomes inhibits resection both in vitro and in vivo ${ }^{57,82}$, these data support the view that failure to remove histones from the DSB ends can 


\section{a}



d

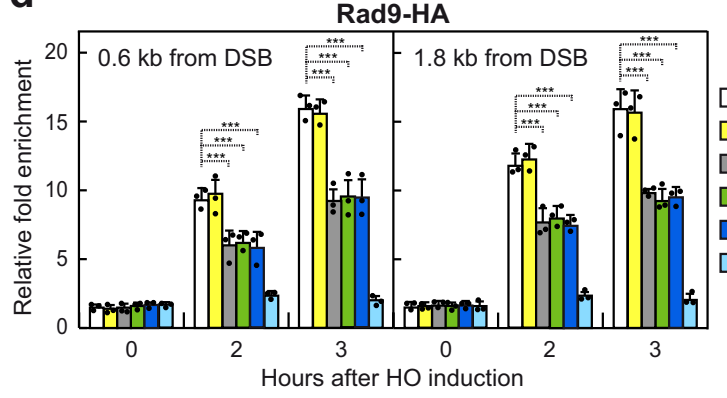

e
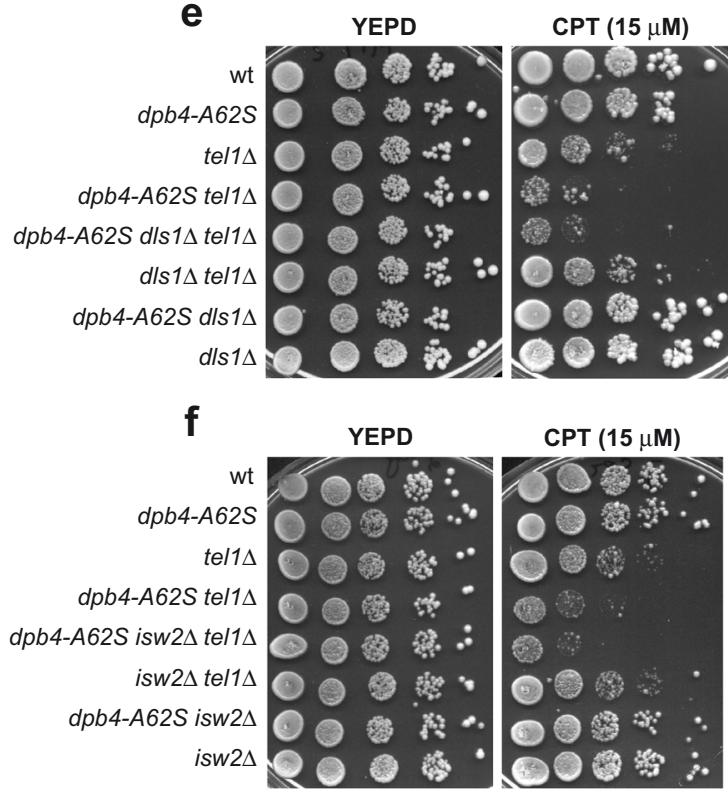
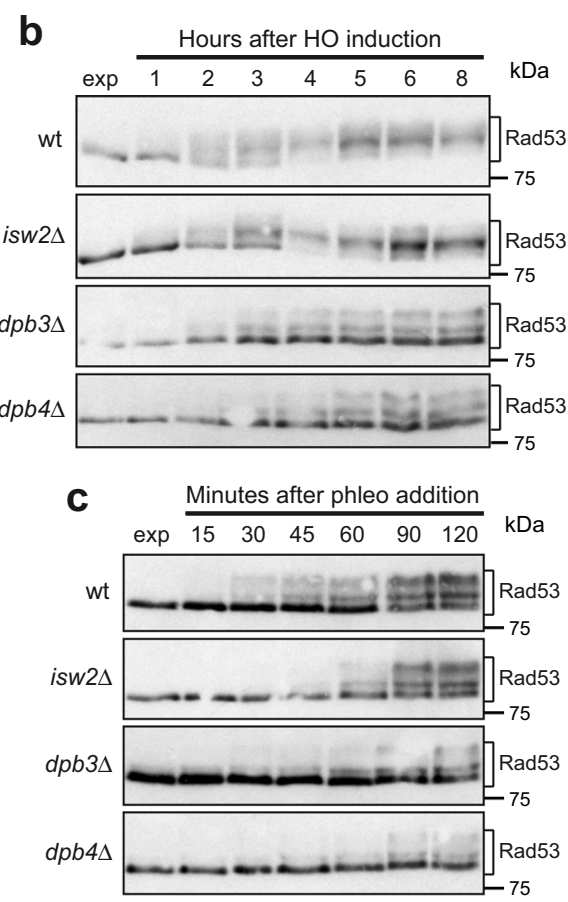

g $\square \mathrm{wt}$

$\square d p b 4-A 62 S$

$\square d p b 4 \Delta$

$\square$ notag Pol2-HA
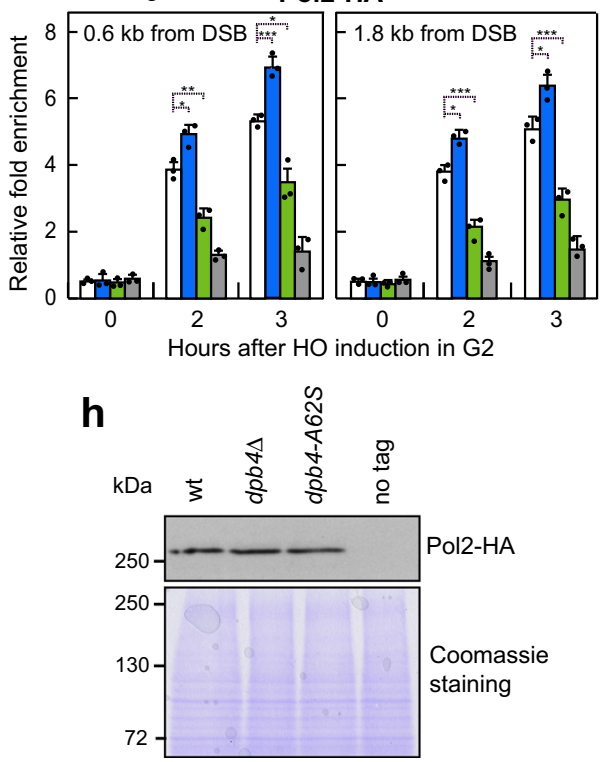

account for the decreased MRX association to DSBs and the resection defect of $d p b 4 \Delta$ cells.

Dpb4 is shared by two highly conserved protein complexes: the chromatin-remodeling ISW2/hCHRAC, which is known to slide nucleosomes by disrupting histone-DNA interactions ${ }^{46,83,84}$, and the Pol $\varepsilon$, which is implicated in DNA replication and heterochromatin maintenance ${ }^{40,41}$. In both complexes, Dpb4 interacts with a histone fold protein, namely Dls1 in the ISW2 complex and $\mathrm{Dpb} 3$ in the Pol $\varepsilon$ complex, to form H2A-H2B-like complexes ${ }^{40,44,45,81}$.
We found that Dpb4 promotes DSB resection by acting with Dls1 and Isw2 subunits of the ISW2 complex, whereas it facilitates Rad9 association to DSBs and checkpoint activation by acting with Dpb3. In fact, similar to DPB4 deletion, the lack of Dls1 or Isw2, but not of Dpb3, severely reduces histone removal from the DSB ends, MRX association to DSBs and DSB resection. By contrast, the lack of Isw2 does not reduce checkpoint activation and Rad9 association to DSBs. Rather, the Dpb4 checkpoint function relies on Dpb4 interaction with Dpb3, whose lack reduces Rad9 association to DSBs and DSB-induced Rad53 
Fig. 7 The lack of Dpb3, but not of Isw2, impairs Rad9 association to DSB and checkpoint activation. a DSB resection. YEPR exponentially growing cell cultures were transferred to YEPRG at time zero to induce HO production. Sspl-digested genomic DNA was analyzed as in Fig. 2a. The experiment was performed independently three times with similar results; see Supplementary Figure 4 for the densitometric analysis of the resection products from three independent experiments as in $\mathbf{a}$. b YEPR exponentially growing cell cultures of JKM139 derivative strains were transferred to YEPRG at time zero to induce HO. Protein extracts were subjected to western blot analysis with anti-Rad53 antibodies. c Phleomycin (10 $\mu \mathrm{g} / \mathrm{mL})$ was added to exponentially growing cells followed by western blot analysis with anti-Rad53 antibodies. The experiments in $\mathbf{b}$ and $\mathbf{c}$ were performed independently two times with similar results. d Exponentially growing YEPR cell cultures of JKM139 derivative strains were transferred to YEPRG to induce HO expression. Relative fold enrichment of Rad9-HA at the HO-induced DSB was evaluated after ChIP with anti-HA antibody and qPCR. The mean values of three independent experiments are represented with error bars denoting s.d. ${ }^{\star \star \star} p<0.005$ (unpaired two-tailed Student's $t$-test). e, $\mathbf{f}$ Serial dilutions of exponentially growing cultures onto YEPD plates with or without CPT. $\mathbf{g} \mathrm{HO}$ expression was induced at time zero by galactose addition to G2-arrested cells that were kept arrested in G2 by nocodazole. Relative fold enrichment of Pol2-HA at the HO-induced DSB was evaluated after ChIP with anti-HA antibody and qPCR. The mean values of three independent experiments are represented with error bars denoting s.d. ${ }^{\star \star \star} p<0.005 ;{ }^{\star \star} p<0.01 ;{ }^{*} p<0.05$ (unpaired two-tailed Student's $t$-test). $\mathbf{h}$ Western blot with anti-HA antibodies of protein extracts from G2-arrested cells. The experiment was performed independently three times with similar results.

phosphorylation. The lack of Dpb4 does not further reduce Rad9 persistence at DSBs in $d p b 3 \Delta$ cells, indicating that Dpb3 and Dpb4 promote Rad9 association to DSBs by acting in the same pathway. The Dpb4-mediated histone removal and Rad9 loading to DSBs occurs independently to each other, as the lack of Isw2 impairs histone removal from DSBs but not Rad9 association to DSBs, whereas the lack of Dpb3 impairs Rad9 association to DSBs but not histone removal from DSBs. Furthermore, the finding that $d p b 3 \Delta$ cells, but not isw2 $\Delta$ cells, showed reduced Rad53 activation indicates that the checkpoint defect of $d p b 4 \Delta$ cells is caused by the decreased Rad9 association at DSBs, rather than by the reduced amount of ssDNA caused by defective resection.

The function of Dpb4 in promoting Isw2 and Rad9 association to DSBs is enhanced by the A62S mutation that leads to an increased Dpb4 persistence at DSBs, suggesting that the Dpb4 functions in both chromatin-remodeling and checkpoint activation rely on its DNA binding property. Interestingly, although the A62S mutation slightly reduces the DNA binding affinity of both Dpb3-Dpb4 and Dls1-Dpb4 complexes, it favors the formation of higher-order DNA-Dpb3-Dpb4 and DNA-Dls1-Dpb4 complexes. Although the nature of these complexes requires further investigation, their formation suggests that the increased amount of chromatin-bound Dpb4 $4^{\mathrm{A} 62 \mathrm{~S}}$ detected by ChIP is due to a transition to high stoichiometry protein-DNA complexes.

The Dpb4 ${ }^{\mathrm{A} 62 \mathrm{~S}}$ mutant variant enhances Isw2 association to DSBs but reduces histone removal from the DSB ends. Similarly, deletion of the negatively charged $\mathrm{C}$ terminus of the $D$. melanogaster Dpb4 ortholog enhances DNA binding but inhibits nucleosome sliding ${ }^{59}$, suggesting that not only a poor, but also an increased Isw2 persistence to DSBs impairs Isw2 activity. As nucleosome mobilization by Isw2 involves DNA translocation inside the nucleosome that requires Isw2 ability to break and reform DNA-histone contacts ${ }^{85}$, increasing the interaction between Isw2 and the nucleosomal DNA might enhance the energetic barrier to nucleosome repositioning, thus explaining the histone removal defect of $d p b 4-A 62 S$ cells.

The Dpb3-Dpb4 complex is flexibly tethered to the core subunits of Pol $\varepsilon^{35}$, which was previously shown to activate a checkpoint in response to DNA replication stress independently of the 9-1-1 complex ${ }^{76-79}$. This finding raises the question of whether Dpb3-Dpb4 dimer acts through Pol $\varepsilon$ to activate the checkpoint. We found that Pol2 is recruited to DSBs independently of DNA replication and Dpb4 ${ }^{\mathrm{A} 62 \mathrm{~S}}$ leads to an increased Pol2 association at DSBs, suggesting that Dpb4 might act within the Pol $\varepsilon$ holoenzyme to enhance Rad9 association to DSBs and checkpoint activation.

One possibility is that $\mathrm{Dpb} 4$ promotes Rad9 association to DSBs by directly recruiting Rad9 to the DSB sites. However, we failed to detect any interaction between $\mathrm{Dpb} 4$ and Rad9 by coimmunoprecipitation. Interestingly, Dpb4 promotes Rad9 association to DSBs by acting in the same pathway of Dot1, which is known to drive Rad9 association to DSBs by catalyzing H3-K79 methylation. H3-K79 is constitutively methylated by Dot 1 in both mammalian and yeast cells ${ }^{68,69,86}$. Furthermore, at least in human cells, irradiation does not lead to increased histone H3-K79 methylation $^{67}$, raising the question of how DNA DSBs expose methylated $\mathrm{H} 3-\mathrm{K} 79$ to Rad9 recognition. The Dpb3-Dpb4 complex has been shown to bind histones $\mathrm{H} 3$ and $\mathrm{H} 4$ in the context of chromatin, and to possess intrinsic $\mathrm{H} 3-\mathrm{H} 4$ chaperone and DNA supercoiling activities ${ }^{38,39}$. Thus, it would be tempting to speculate that the Dpb3-Dpb4 complex, possibly as part of the Pol $\varepsilon$ holoenzyme, induces re-deposition/exchange of histones $\mathrm{H} 3$ and $\mathrm{H} 4$ at the DSB ends, where subsequent $\mathrm{H} 3$ methylation by Dot1 would lead to exposure of histone H3 to Rad9 recognition (Fig. 8g).

In conclusion, we propose that the Dls1-Dpb4 dimer binds the DSB ends and facilitates the loading of the ISW2/hCHRAC complex, which in turn promotes MRX association to DSBs and DSB resection by sliding/removing nucleosomes from the DSB ends (Fig. 8g). The Dpb3-Dpb4 complex, in turn, promotes Rad9 association to the DSB and checkpoint activation by inducing exposure of histone $\mathrm{H} 3$ to Rad9 binding. Because Dpb4 is evolutionarily conserved, it will be interesting to investigate whether, depending on its interactors, it plays similar roles in DSB resection and checkpoint activation also in mammalian cells.

\section{Methods}

Yeast strains and media. S. cerevisiae is the experimental model used in this study. Strain genotypes are listed in Supplementary Table 1. Strain JKM139, used to detect DSB resection and to perform ChIP analysis, was kindly provided by J. Haber (Brandeis University, Waltham, USA). The ddc1-T602A and the rad9-STAA alleles were kindly provided by J. Diffley (The Francis Crick Institute, London UK) and B. Pfander (Max Planck Institute of Biochemistry, Martinsried, Germany). Gene disruptions and tag fusions were generated by one-step PCR and standard yeast transformation procedure. Primers used for disruptions and gene tagging are listed in Supplementary Table 2. Cells were grown in YEP medium (1\% yeast extract, $2 \%$ bactopeptone) supplemented with 2\% glucose (YEPD), $2 \%$ raffinose (YEPR) or $2 \%$ raffinose and $3 \%$ galactose (YEPRG). All experiments were performed at $26^{\circ} \mathrm{C}$.

Search for mutations that sensitize tel1s cells to CPT. To search for mutations that sensitize tell $\Delta$ cells to CPT, tell $\Delta$ cells were mutagenized with ethyl methanesulfonate and plated on YEPD plates. Approximately 100000 survival colonies were replica plated on YEPD plates with or without CPT. Clones sensitive to CPT were transformed with a plasmid containing wild-type TEL1 to identify those that lost the DNA damage hypersensitivity. The corresponding original clones were then crossed with wild-type cells to identify by tetrad analysis the clones in which the increased DNA damage sensitivity was due to the simultaneous presence of tell $\Delta$ and a single-gene mutation. This mutation was identified by genome sequencing and genetic analyses. To confirm that the $d p b 4-A 62 S$ mutation was responsible for the increased DNA damage sensitivity of tell $\triangle$ cells, a KANMX gene was integrated downstream of the $d p b 4-A 62 S$ stop codon and the resulting 
a



C




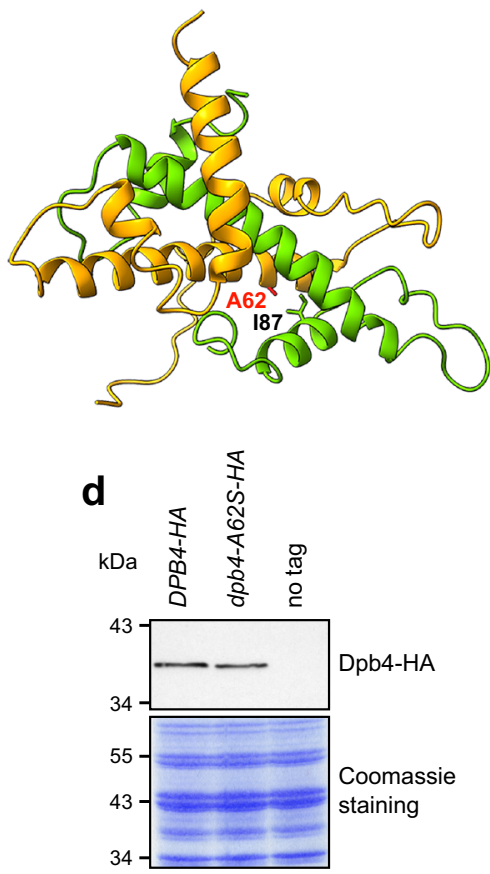

e

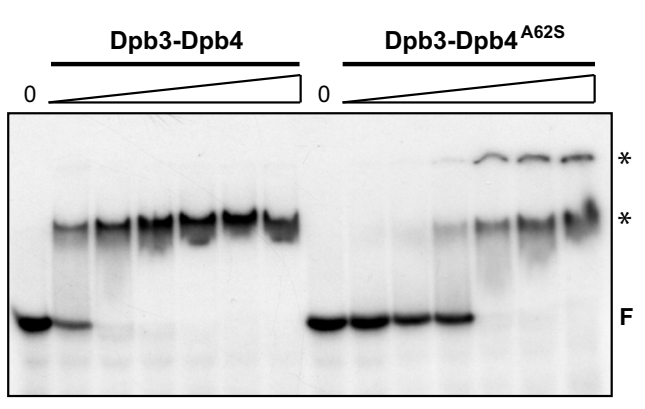

f


g

DSB

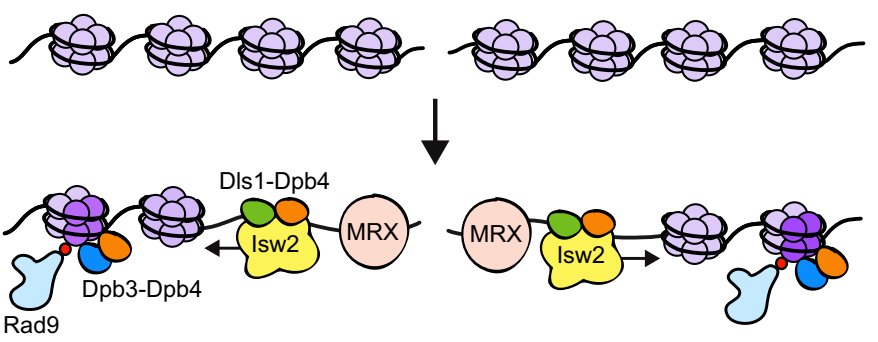

Fig. 8 Effect of the A62S mutation on the DNA binding properties of Dpb3-Dpb4 and Dls1-Dpb4 heterodimers. a Representation of Dpb4, Dpb3, and Dls1 proteins. The histone fold domain (HF) is shown. b 3D structure of Dpb4-Dpb3 and Dpb4-Dls1 heterodimers. The histone fold domain of Dpb4 is in orange, while that of Dpb3 and Dls1 is in light blue and green, respectively. A62 is shown as a red stick. The 3D structure of Dpb4-Dpb3 was extracted from PDB 6WJV35, while the 3D model of DIs1 was built using I-TASSER ${ }^{90}$. $\mathbf{c H O}$ expression was induced at time zero by galactose addition to G2-arrested cells that were kept arrested in G2 by nocodazole. Relative fold enrichment of Dpb4-HA and Dpb4-A62S-HA compared to untagged Dpb4 (no tag) was evaluated after ChIP with anti-HA antibodies and qPCR analysis. The mean values of three independent experiments are represented with error bars denoting s.d. ${ }^{\star \star \star} p<0.005$ (unpaired two-tailed Student's $t$-test). d Western blot with anti-HA antibodies of protein extracts from G2-arrested cells. The experiment was performed independently three times with similar results. e, fEMSA with a 61 bp dsDNA and increasing concentrations of Dpb3-Dpb4 and Dpb3-Dpb4A62S (e), and Dls1-Dpb4 and Dls1-Dpb4A62S (f) complexes. Bands corresponding to free DNA (F), and protein-DNA complexes with higher stoichiometry (asterisk) are denoted. The experiments were performed independently two times with similar results. $\mathbf{g}$ Model for Dpb4 function at DSBs. After DSB formation, the Dls1-Dpb4 dimer promotes the association of Isw2 to DSBs, which catalyzes nucleosome sliding/removal and facilitates MRX association to them. The Dpb3-Dpb4 dimer, possibly in complex with Pol $\varepsilon$, in turn, uses its histone chaperone activity to induce re-deposition/exchange of $\mathrm{H} 3$ and $\mathrm{H} 4$ histones (dark violet), whose subsequent $\mathrm{H} 3$ methylation by Dot1 (red dots) leads to H3 exposure to Rad9 recognition. 
strain was crossed to tel1 $\Delta$ cells to verify by tetrad dissection that the increased CPT sensitivity cosegregated with TEL1 deletion and the KANMX allele.

DSB resection. YEPR exponentially growing cell cultures of JKM139 derivative strains, carrying the HO cut site at the MAT locus, were transferred to YEPRG at time zero. SspI-digested genomic DNA was run on alkaline agarose gels and visualized after hybridization with a single-stranded RNA probe that anneals with the unresected strand at one side of the HO-induced DSB ${ }^{87}$. This probe was obtained by in vitro transcription using Promega Riboprobe System-T7 and plasmid pML514 as a template. Plasmid pML514 was constructed by inserting in the pGEM7Zf EcoRI site a 900-bp fragment containing part of the MAT locus (coordinates 200870 to 201587 on chromosome III). Quantitative analysis of DSB resection was performed by calculating the ratio of band intensities for ssDNA and the total amount of DSB products. The resection efficiency was normalized with respect to the HO cleavage efficiency for each time point. Densitometric analysis of band intensities was performed using Scion Image Beta 4.0.2 software.

Spot assays. Cells grown overnight were diluted to $1 \times 10^{7}$ cells $/ \mathrm{mL}$. 10-fold serial dilutions were spotted on YEPD with or without DNA damaging drugs. Plates were incubated for 3 days at $28^{\circ} \mathrm{C}$

Western blotting. Protein extracts for western blot analysis were prepared by trichloroacetic acid (TCA) precipitation. Frozen cell pellets were resuspended in $100 \mu \mathrm{L} 20 \%$ TCA. After the addition of acid-washed glass beads, the samples were vortexed for $10 \mathrm{~min}$. The beads were washed with $200 \mu \mathrm{L}$ of 5\% TCA twice, and the extract was collected in a new tube. The crude extract was precipitated by centrifugation at $850 \times \mathrm{g}$ for $10 \mathrm{~min}$. TCA was discarded and samples were resuspended in $70 \mu \mathrm{L} 6 \times$ Laemmli buffer $(60 \mathrm{mM}$ Tris $\mathrm{pH} 6.8,2 \%$ SDS, $10 \%$ glycerol, $100 \mathrm{mM}$ DTT, $0.2 \%$ bromophenol blue) and $30 \mu \mathrm{L} 1 \mathrm{M}$ Tris $\mathrm{pH}$ 8.0. Prior to loading, samples were boiled at $95^{\circ} \mathrm{C}$ and centrifuged at $850 \times g$ for $10 \mathrm{~min}$. The supernatant containing the solubilized proteins was separated on $10 \%$ polyacrylamide gels. Rad53 was detected by using anti-Rad53 polyclonal antibodies (ab104232) (1:2000) from Abcam.

HA- or Myc-tagged proteins were detected by using anti-HA (12CA5) (1:2000) or anti-Myc (9E10) (1:1000) antibodies, respectively.

\section{Chromatin immunoprecipitation and qPCR. YEPR exponentially growing cell} cultures of JKM139 derivative strains, carrying the HO cut site at the MAT locus, were transferred to YEPRG at time zero. Crosslinking was done with $1 \%$ formaldehyde for $5 \mathrm{~min}$ (Mre11), $10 \mathrm{~min}$ (Rad9), or $15 \mathrm{~min}$ (Dpb4, Dpb4 ${ }^{\mathrm{A} 62 \mathrm{~S}}$, Pol2, Isw2, $\mathrm{H} 3$, and $\mathrm{H} 2 \mathrm{~A}$ ). The reaction was stopped by adding $0.125 \mathrm{M}$ glycine for 5 min. Immunoprecipitation was performed by incubating samples with Dynabeads Protein $\mathrm{G}$ (ThermoFisher Scientific) for $3 \mathrm{~h}$ at $4{ }^{\circ} \mathrm{C}$ in the presence of $5 \mu \mathrm{g}$ anti-HA (12CA5) or anti-Myc antibodies (9E10). H2A and H3 histones were immunoprecipitated by using $5 \mu \mathrm{g}$ anti-H2A (39945, Active Motif) and $4 \mu \mathrm{g}$ anti-H3 (ab1791, Abcam) antibodies, respectively. Quantification of immunoprecipitated DNA was achieved by qPCR on a Bio-Rad CFX Connect ${ }^{\text {tw }}$ Real-Time System apparatus and Bio-Rad CFX Maestro 1.1 software. Triplicate samples in $20 \mu \mathrm{L}$ reaction mixture containing $10 \mathrm{ng}$ of template DNA, $300 \mathrm{nM}$ for each primer, $2 \times$ SsoFast ${ }^{\text {tx }}$ EvaGreen ${ }^{\circledast}$ supermix (Bio-Rad \#1725201) ( $2 \times$ reaction buffer with dNTPs, Sso7d-fusion polymerase, $\mathrm{MgCl}_{2}$, EvaGreen dye, and stabilizers) were run in white 96-well PCR plates Multiplate ${ }^{\mathrm{m}}$ (Bio-Rad \#MLL9651). The qPCR program was as follows: step $1,98^{\circ} \mathrm{C}$ for $2 \mathrm{~min}$; step $2,90^{\circ} \mathrm{C}$ for $5 \mathrm{~s}$; step $3,60^{\circ} \mathrm{C}$ for $15 \mathrm{~s}$; step 4, return to step 2 and repeat 40 times. At the end of the cycling program, a melting program (from 65 to $95^{\circ} \mathrm{C}$ with a $0.5^{\circ} \mathrm{C}$ increment every $5 \mathrm{~s}$ ) was run to test the specificity of each qPCR. Data are expressed as fold enrichment at the HOinduced DSB over that at the non-cleaved ARO1 locus, after normalization of the ChIP signals to the corresponding input for each time point. Fold enrichment was then normalized to the efficiency of DSB induction. For histone loss, the fold enrichment from each sample after HO induction was divided by the fold enrichment from uninduced cells, and $\log _{2}$ of the resulting values was calculated. Oligonucleotides used for qPCR analyses are listed in Supplementary Table 3.

Coimmunoprecipitation. Total protein extracts were prepared by breaking cells in $400 \mu \mathrm{L}$ of buffer containing $50 \mathrm{mM}$ HEPES pH 7.5, $300 \mathrm{mM} \mathrm{NaCl}, 20 \%$ glycerol, 1 $\mathrm{mM}$ sodium orthovanadate, $60 \mathrm{mM} \beta$-glycerophosphate and protease inhibitor cocktail (Roche Diagnostics). An equal volume of breaking buffer was added to clarified protein extracts and tubes were incubated for $2 \mathrm{~h}$ at $4{ }^{\circ} \mathrm{C}$ with $50 \mu \mathrm{L}$ of Protein G-Dynabeads and $5 \mu \mathrm{g}$ anti-HA (12CA5) antibodies. The resins were then washed twice with $1 \mathrm{~mL}$ of breaking buffer and once with $1 \mathrm{~mL}$ PBS. Bound proteins were visualized by western blotting with anti-HA (12CA5) (1:2000) or anti-Myc (9E10) (1:1000) antibodies after electrophoresis on a 10 or 15\% SDSpolyacrylamide gel.

Purification of Dpb3-Dpb4 and DIs1-Dpb4 heterodimers. Design, expression and purification of Dpb4 heterodimers were performed as previously described ${ }^{88}$. Briefly, the genes coding for Dpb4, Dpb4 ${ }^{\mathrm{A} 62 S}$, Dpb3, and Dls1 were optimized for the expression in E. coli cells and chemically synthesized (Genscript, Piscataway,
NJ, USA). DPB4 and DPB4-A62S genes were cloned in frame with a C-terminal 6xHis-Tag into pET-21a vector (EMD, Millipore, Billerica, MA, USA) between NdeI and XhoI sites. The DPB3 and DLS1 genes were cloned in frame with a Cterminal Strep-Tag into a modified pET-28 vector between NcoI and XhoI sites. E. coli BL21 (DE3) cells were co-transformed with the above plasmids to obtain Dpb3-Dpb4, Dpb3-Dpb4 ${ }^{\mathrm{A} 62 \mathrm{~S}}$, Dls1-Dpb4, and Dls1-Dpb4 ${ }^{\mathrm{A} 62 \mathrm{~S}}$ heterodimers. Transformed cells were selected on LB agar plates supplemented with ampicillin $(100 \mathrm{mg} / \mathrm{L})$ and kanamycin $(50 \mathrm{mg} / \mathrm{L})$. Heterodimers were produced in autoinduction ZYM-5052 medium ${ }^{89}$ supplemented with ampicillin $(100 \mathrm{mg} / \mathrm{L})$ and kanamycin $(50 \mathrm{mg} / \mathrm{L})$, extracted and purified by immobilized ion metal affinity chromatography (Jena Bioscience, Jena, Germany) followed by Strep purification on Strep-Tactin resin (IBA Lifesciences, Gottingen, Germany). High-concentrated fractions were buffer-exchanged with phosphate buffer $(10 \mathrm{mM}, \mathrm{pH} 7)$ by gel filtration on PD-10 columns (GE Healthcare, Little Chalfont, UK). Protein concentration was determined by the Bradford assay (Bio-Rad, Hercules, USA), using bovine serum albumin as a standard. SDS-PAGE was performed on $14 \%$ acrylamide gels and stained with Gel-Code Blue (Pierce, Rockford, USA) after electrophoresis. Broad-range, pre-stained molecular-mass markers (GeneSpin, Milan, Italy) were used as standards.

Circular dichroism spectroscopy. CD spectra of purified proteins were obtained in phosphate buffer at the concentration of $2 \mu \mathrm{M}$ with a J-815 spectropolarimeter (JASCO, Europe, Lecco, Italy), using a $0.1-\mathrm{cm}$ path length cuvette. Spectra were collected in the 190-260 range with $0.2 \mathrm{~nm}$ data pitch and $20 \mathrm{~nm} / \mathrm{min}$ scanning speed. All spectra were corrected for buffer contribution, averaged from four independent acquisitions, and smoothed by using a third-order least-square polynomial fit. Thermal denaturation ramps were obtained measuring the variation of CD signal at $208 \mathrm{~nm}$ when progressively heating the sample from 25 to $90^{\circ} \mathrm{C}$. Data were analyzed with OriginPro 2020 (OriginLab Corporation, Northampton, USA). Measurements were performed in triplicate.

Electrophoretic mobility shift assay (EMSA). EMSA was performed by incubating 1.5 pmol of 61 bp ${ }^{32}$ P-labeled dsDNA (5'-GACGCTGCCGAATTCTAC CAGTGCCTTGCTAGGACATCTTTGCCCACCTGCAGGTTCACCC- $\left.3^{\prime}\right)^{43}$ with purified Dpb3-Dpb4 and Dpb3-Dpb4 ${ }^{\mathrm{A} 62 \mathrm{~S}}(0,0.75,1.5,3,7,13,20 \mathrm{pmol})$ or Dls1-Dpb4 and Dls1-Dpb4 ${ }^{\mathrm{A} 62 \mathrm{~S}}(0,20,40,80,100,120,160 \mathrm{pmol})$ in ice for $10 \mathrm{~min}$ in binding buffer (20 mm HEPES-NaOH pH 7.5, $0.5 \mathrm{mM}$ EDTA, 0.05\% NP-40, $10 \%(\mathrm{v} / \mathrm{v})$ glycerol and $60 \mu \mathrm{g} / \mathrm{mL}$ BSA) to a final volume of $50 \mu \mathrm{L}$. Reactions were loaded on a non-denaturing $6 \%$ acrylamide/bisacrylamide gel and separated by running for $2 \mathrm{~h}$ at $150 \mathrm{~V}$ at $4{ }^{\circ} \mathrm{C}$ using a low-ionic strength buffer $(6.73 \mathrm{mM}$ Tris$\mathrm{HCl} \mathrm{pH} \mathrm{7.5,} \mathrm{3.3} \mathrm{mM} \mathrm{NaOAc} \mathrm{pH} 5$ and $1 \mathrm{mM}$ EDTA). Gels were soaked for $15 \mathrm{~min}$ in $10 \%$ methanol, $10 \%$ acetic acid solution, vacuum-dried and exposed to an autoradiography film.

3D modeling. The 3D structure of the $\mathrm{Dpb} 3-\mathrm{Dpb} 4$ heterodimer was extracted from PDB 6WJV 35 . The 3D model of Dls1 was predicted by I-TASSER web server $^{90}$ and superimposed on the 3D structure of Dpb3 in the Dpb4-Dpb3 heterodimer using Pymol 2.4.1 software. The figures were prepared using UCSF Chimera X 0.93 software $^{91}$

Statistical analysis. Statistical analysis was performed using Microsoft Excel Professional 365 software. $P$-values were determined by using an unpaired twotailed $t$-test. No statistical methods or criteria were used to estimate the size or to include or exclude samples.

Reporting summary. Further information on research design is available in the Nature Research Reporting Summary linked to this article.

\section{Data availability}

All data are in the paper and Supplementary Information. The structure of Dpb4/Dpb3 was extracted from PDB 6WJV. All data are available from the authors upon reasonable request. Source data are provided with this paper.

Received: 20 December 2020; Accepted: 20 July 2021; Published online: 06 August 2021

\section{References}

1. Lieber, M. R. The mechanism of double-strand DNA break repair by the nonhomologous DNA end-joining pathway. Annu. Rev. Biochem. 79, 181-211 (2010).

2. Mehta, A. \& Haber, J. E. Sources of DNA double-strand breaks and models of recombinational DNA repair. Cold Spring Harb. Perspect. Biol. 6, a016428 (2014). 
3. Bonetti, D., Colombo, C. V., Clerici, M. \& Longhese, M. P. Processing of DNA ends in the maintenance of genome stability. Front. Genet. 9, 390 (2018)

4. Syed, A. \& Tainer, J. A. The MRE11-RAD50-NBS1 complex conducts the orchestration of damage signaling and outcomes to stress in DNA replication and repair. Annu. Rev. Biochem. 87, 263-294 (2018).

5. Cannavo, E. \& Cejka, P. Sae2 promotes dsDNA endonuclease activity within Mre11-Rad50-Xrs2 to resect DNA breaks. Nature 514, 122-125 (2014).

6. Mimitou, E. P. \& Symington, L. S. Sae2, Exo1 and Sgs1 collaborate in DNA double-strand break processing. Nature 455, 770-774 (2008).

7. Zhu, Z., Chung, W. H., Shim, E. Y., Lee, S. E. \& Ira, G. Sgs1 helicase and two nucleases Dna2 and Exo1 resect DNA double-strand break ends. Cell 134, 981-994 (2008).

8. Cejka, P. et al. DNA end resection by Dna2-Sgs1-RPA and its stimulation by Top3-Rmil and Mre11-Rad50-Xrs2. Nature 467, 112-116 (2010)

9. Niu, H. et al. Mechanism of the ATP-dependent DNA end-resection machinery from Saccharomyces cerevisiae. Nature 467, 108-111 (2010).

10. Garcia, V., Phelps, S. E. L., Gray, S. \& Neale, M. J. Bidirectional resection of DNA double-strand breaks by Mre11 and Exol. Nature 479, 241-244 (2011).

11. Shibata, A. et al. DNA double-strand break repair pathway choice is directed by distinct MRE11 nuclease activities. Mol. Cell 53, 7-18 (2014).

12. Reginato, G., Cannavo, E. \& Cejka, P. Physiological protein blocks direct the Mre11-Rad50-Xrs2 and Sae2 nuclease complex to initiate DNA end resection. Genes Dev. 31, 2325-2330 (2017).

13. Wang, W., Daley, J. M., Kwon, Y., Krasner, D. S. \& Sung, P. Plasticity of the Mre11-Rad50-Xrs2-Sae2 nuclease ensemble in the processing of DNA-bound obstacles. Genes Dev. 31, 2331-2336 (2017).

14. Zhou, C. Y., Johnson, S. L., Gamarra, N. I. \& Narlikar, G. J. Mechanisms of ATP-dependent chromatin remodeling motors. Annu. Rev. Biophys. 45, 153-181 (2016).

15. Chai, B., Huang, J., Cairns, B. R. \& Laurent, B. C. Distinct roles for the RSC and Swi/Snf ATP-dependent chromatin remodelers in DNA double-strand break repair. Genes Dev. 19, 1656-1661 (2005).

16. Shim, E. Y. et al. RSC mobilizes nucleosomes to improve accessibility of repair machinery to the damaged chromatin. Mol. Cell Biol. 27, 1602-1613 (2007).

17. Wiest, N. E., Houghtaling, S., Sanchez, J. C., Tomkinson, A. E. \& Osley, M. A. The SWI/SNF ATP-dependent nucleosome remodeler promotes resection initiation at a DNA double-strand break in yeast. Nucleic Acids Res. 45, 5887-5900 (2017).

18. Morrison, A. J. et al. INO80 and gamma-H2AX interaction links ATP-dependent chromatin remodeling to DNA damage repair. Cell 119, 767-775 (2004).

19. van Attikum, H., Fritsch, O., Hohn, B. \& Gasser, S. M. Recruitment of the INO80 complex by H2A phosphorylation links ATP-dependent chromatin remodeling with DNA double-strand break repair. Cell 119, 777-788 (2004).

20. van Attikum, H., Fritsch, O. \& Gasser, S. M. Distinct roles for SWR1 and INO80 chromatin remodeling complexes at chromosomal double-strand breaks. EMBO J. 26, 4113-4125 (2007)

21. Tsukuda, T. et al. INO80-dependent chromatin remodeling regulates early and late stages of mitotic homologous recombination. DNA Repair 8, 360-369 (2009).

22. Ciccia, A. \& Elledge, S. J. The DNA damage response: making it safe to play with knives. Mol. Cell 40, 179-204 (2010).

23. Villa, M., Cassani, C., Gobbini, E., Bonetti, D. \& Longhese, M. P. Coupling end resection with the checkpoint response at DNA double-strand breaks. Cell. Mol. Life. Sci. 73, 3655-3663 (2016).

24. Gilbert, C. S., Green, C. M. \& Lowndes, N. F. Budding yeast Rad9 is an ATPdependent Rad53 activating machine. Mol. Cell 8, 129-136 (2001).

25. Schwartz, M. F. et al. Rad9 phosphorylation sites couple Rad53 to the Saccharomyces cerevisiae DNA damage checkpoint. Mol. Cell 9, 1055-1065 (2002).

26. Sweeney, F. D. et al. Saccharomyces cerevisiae Rad9 acts as a Mec1 adaptor to allow Rad53 activation. Curr. Biol. 15, 1364-1375 (2005).

27. Mordes, D. A., Nam, E. A. \& Cortez, D. Dpb11 activates the Mec1-Ddc2 complex. Proc. Natl Acad. Sci. USA 105, 18730-18734 (2008).

28. Navadgi-Patil, V. M. \& Burgers, P. M. Yeast DNA replication protein Dpb11 activates the Mec1/ATR checkpoint kinase. J. Biol. Chem. 283, 35853-35859 (2008).

29. Navadgi-Patil, V. M. \& Burgers, P. M. The unstructured C-terminal tail of the 9-1-1 clamp subunit Ddc1 activates Mec1/ATR via two distinct mechanisms. Mol. Cell 36, 743-753 (2009).

30. Wang, H. \& Elledge, S. J. Genetic and physical interactions between DPB11 and $D D C 1$ in the yeast DNA damage response pathway. Genetics 160 , 1295-1304 (2002).

31. Puddu, F. et al. Phosphorylation of the budding yeast 9-1-1 complex is required for Dpb11 function in the full activation of the UV-induced DNA damage checkpoint. Mol. Cell. Biol. 28, 4782-4793 (2008).

32. Pfander, B. \& Diffley, J. F. Dpb11 coordinates Mecl kinase activation with cell cycle-regulated Rad9 recruitment. EMBO J. 30, 4897-4907 (2011).

33. Muramatsu, S., Hirai, K., Tak, Y. S., Kamimura, Y. \& Araki, H. CDKdependent complex formation between replication proteins Dpb11, Sld2, Pol epsilon, and GINS in budding yeast. Genes Dev. 24, 602-612 (2010).
34. Goswami, P. et al. Structure of DNA-CMG-Pol epsilon elucidates the roles of the non-catalytic polymerase modules in the eukaryotic replisome. Nat. Commun. 9, 5061 (2018).

35. Yuan, Z., Georgescu, R., Schauer, G. D., O’Donnell, M. E. \& Li, H. Structure of the polymerase epsilon holoenzyme and atomic model of the leading strand replisome. Nat. Commun. 11, 3156 (2020).

36. Araki, H. et al. Cloning DPB3, the gene encoding the third subunit of DNA polymerase II of Saccharomyces cerevisiae. Nucleic Acids Res. 19, 4867-4872 (1991).

37. Ohya, T., Maki, S., Kawasaki, Y. \& Sugino, A. Structure and function of the fourth subunit (Dpb4p) of DNA polymerase epsilon in Saccharomyces cerevisiae. Nucleic Acids Res. 28, 3846-3852 (2000).

38. Bellelli, R. et al. POLE3-POLE4 is a histone H3-H4 chaperone that maintains chromatin integrity during DNA replication. Mol. Cell 72, 112-126 (2018).

39. Yu, C. et al. A mechanism for preventing asymmetric histone segregation onto replicating DNA strands. Science 361, 1386-1389 (2018).

40. Iida, T. \& Araki, H. Noncompetitive counteractions of DNA polymerase epsilon and ISW2/yCHRAC for epigenetic inheritance of telomere position effect in Saccharomyces cerevisiae. Mol. Cell. Biol. 24, 217-227 (2004).

41. Tsubota, T. et al. Double-stranded DNA binding, an unusual property of DNA polymerase epsilon, promotes epigenetic silencing in Saccharomyces cerevisiae. J. Biol. Chem. 281, 32898-32908 (2006).

42. He, H. et al. Coordinated regulation of heterochromatin inheritance by Dpb3 Dpb4 complex. Proc. Natl Acad. Sci. USA 114, 12524-12529 (2017).

43. Tsubota, T., Maki, S., Kubota, H., Sugino, A. \& Maki, H. Double-stranded DNA binding properties of Saccharomyces cerevisiae DNA polymerase epsilon and of the Dpb3p-Dpb4p subassembly. Genes Cells 8, 873-888 (2003).

44. Corona, D. F. et al. Two histone fold proteins, CHRAC-14 and CHRAC-16, are developmentally regulated subunits of chromatin accessibility complex (CHRAC). EMBO J. 19, 3049-3059 (2000).

45. Poot, R. A. et al. HuCHRAC, a human ISWI chromatin remodelling complex contains hACF1 and two novel histone-fold proteins. EMBO J. 19, 3377-3387 (2000).

46. Clapier, C. R., Iwasa, J., Cairns, B. R. \& Peterson, C. L. Mechanisms of action and regulation of ATP-dependent chromatin-remodelling complexes. Nat. Rev. Mol. Cell. Biol. 18, 407-422 (2017).

47. McConnell, A. D., Gelbart, M. E. \& Tsukiyama, T. Histone fold protein Dls1p is required for Isw2-dependent chromatin remodeling in vivo. Mol. Cell. Biol. 24, 2605-2613 (2004).

48. Smeenk, G. et al. Poly(ADP-ribosyl)ation links the chromatin remodeler SMARCA5/SNF2H to RNF168-dependent DNA damage signaling. J. Cell Sci. 126, 889-903 (2013).

49. Sánchez-Molina, S. et al. Role for hACF1 in the G2/M damage checkpoint. Nucleic Acids Res. 39, 8445-8456 (2011)

50. Lan, L. et al. The ACF1 complex is required for DNA double-strand break repair in human cells. Mol. Cell 40, 976-987 (2010).

51. Menin, L. et al. Tel1/ATM prevents degradation of replication forks that reverse after topoisomerase poisoning. EMBO Rep. 19, e45535 (2018).

52. Deng, C., Brown, J. A., You, D. \& Brown, J. M. Multiple endonucleases function to repair covalent topoisomerase I complexes in Saccharomyces cerevisiae. Genetics 170, 591-600 (2005).

53. Cassani, C. et al. Tel1 and Rif2 regulate MRX function in end-tethering and repair of DNA double-strand breaks. PLoS Biol. 14, e1002387 (2016).

54. Lee, S. E. et al. Saccharomyces Ku70, Mre11/Rad50 and RPA proteins regulate adaptation to G2/M arrest after DNA damage. Cell 94, 399-409 (1998).

55. Shroff, R. et al. Distribution and dynamics of chromatin modification induced by a defined DNA double-strand break. Curr. Biol. 14, 1703-1711 (2004).

56. Tsukuda, T., Fleming, A. B., Nickoloff, J. A. \& Osley, M. A. Chromatin remodelling at a DNA double-strand break site in Saccharomyces cerevisiae. Nature 438, 379-383 (2005)

57. Adkins, N. L., Niu, H., Sung, P. \& Peterson, C. L. Nucleosome dynamics regulates DNA processing. Nat. Struct. Mol. Biol. 20, 836-842 (2013).

58. Kukimoto, I., Elderkin, S., Grimaldi, M., Oelgeschläger, T. \& Varga-Weisz, P. D. The histone-fold protein complex CHRAC-15/17 enhances nucleosome sliding and assembly mediated by ACF. Mol. Cell 13, 265-277 (2004).

59. Hartlepp, K. F. et al. The histone fold subunits of Drosophila CHRAC facilitate nucleosome sliding through dynamic DNA interactions. Mol. Cell. Biol. 25, 9886-98896 (2005).

60. Gangaraju, V. K., Prasad, P., Srour, A., Kagalwala, M. N. \& Bartholomew, B. Conformational changes associated with template commitment in ATPdependent chromatin remodeling by ISW2. Mol. Cell 35, 58-69 (2009).

61. Zou, L. \& Elledge, S. J. Sensing DNA damage through ATRIP recognition of RPA-ssDNA complexes. Science 300, 1542-1548 (2003).

62. Deshpande, A. M., Ivanova, I. G., Raykov, V., Xue, Y. \& Maringele, L. Polymerase epsilon is required to maintain replicative senescence. Mol. Cell. Biol. 31, 1637-1645 (2011).

63. Gobbini, E. et al. Sae2 function at DNA double-strand breaks is bypassed by dampening Tel1 or Rad53 activity. PLoS Genet. 11, e1005685 (2015). 
64. Giannattasio, M., Lazzaro, F., Plevani, P. \& Muzi-Falconi, M. The DNA damage checkpoint response requires histone H2B ubiquitination by Rad6Bre1 and H3 methylation by Dot1. J. Biol. Chem. 280, 9879-9886 (2005).

65. Wysocki, R. et al. Role of Dot1-dependent histone H3 methylation in G1 and S phase DNA damage checkpoint functions of Rad9. Mol. Cell. Biol. 25, 8430-8443 (2005).

66. Grenon, M. et al. Docking onto chromatin via the Saccharomyces cerevisiae Rad9 Tudor domain. Yeast 24, 105-119 (2007).

67. Huyen, Y. et al. Methylated lysine 79 of histone $\mathrm{H} 3$ targets $53 \mathrm{BP} 1$ to DNA double-strand breaks. Nature 432, 406-411 (2004).

68. Feng, Q. et al. Methylation of H3-lysine 79 is mediated by a new family of HMTases without a SET domain. Curr. Biol. 12, 1052-1058 (2002).

69. van Leeuwen, F., Gafken, P. R. \& Gottschling, D. E. Dot1p modulates silencing in yeast by methylation of the nucleosome core. Cell 109, 745-756 (2002).

70. Granata, M. et al. Dynamics of Rad9 chromatin binding and checkpoint function are mediated by its dimerization and are cell cycle-regulated by CDK1 activity. PLoS Genet. 6, el001047 (2010).

71. Majka, J., Binz, S. K., Wold, M. S. \& Burgers, P. M. J. Replication protein A directs loading of the DNA damage checkpoint clamp to 5'-DNA junctions. J. Biol. Chem. 281, 27855-27861 (2006).

72. Downs, J. A., Lowndes, N. F. \& Jackson, S. P. A role for Saccharomyces cerevisiae histone H2A in DNA repair. Nature 408, 1001-1004 (2000).

73. Toh, G. W. et al. Histone $\mathrm{H} 2 \mathrm{~A}$ phosphorylation and $\mathrm{H} 3$ methylation are required for a novel Rad9 DSB repair function following checkpoint activation. DNA Repair 5, 693-703 (2006).

74. Hammet, A., Magill, C., Heierhorst, J. \& Jackson, S. P. Rad9 BRCT domain interaction with phosphorylated $\mathrm{H} 2 \mathrm{AX}$ regulates the $\mathrm{G} 1$ checkpoint in budding yeast. EMBO Rep. 8, 851-857 (2007).

75. Dang, W., Kagalwala, M. N. \& Bartholomew, B. The Dpb4 subunit of ISW2 is anchored to extranucleosomal DNA. J. Biol. Chem. 282, 19418-19425 (2007).

76. Araki, H., Leem, S. H., Phongdara, A. \& Sugino, A. Dpb11, which interacts with DNA polymerase II(epsilon) in Saccharomyces cerevisiae, has a dual role in S-phase progression and at a cell cycle checkpoint. Proc. Natl Acad. Sci. USA 92, 11791-11795 (1995).

77. Navas, T. A., Zhou, Z. \& Elledge, S. J. DNA polymerase epsilon links the DNA replication machinery to the S phase checkpoint. Cell 80, 29-39 (1995).

78. Wang, H. \& Elledge, S. J. DRC1, DNA replication and checkpoint protein 1, functions with DPB11 to control DNA replication and the S-phase checkpoint in Saccharomyces cerevisiae. Proc. Natl Acad. Sci. USA 96, 3824-3829 (1999).

79. Puddu, F., Piergiovanni, G., Plevani, P. \& Muzi-Falconi, M. Sensing of replication stress and $\mathrm{Mecl}$ activation act through two independent pathways involving the 9-1-1 complex and DNA polymerase $\varepsilon$. PLoS Genet. 7, e1002022 (2011).

80. Aksenova, A. et al. Mismatch repair-independent increase in spontaneous mutagenesis in yeast lacking non-essential subunits of DNA polymerase $\varepsilon$. PLoS Genet. 6, e1001209 (2010).

81. Gnesutta, N., Nardini, M. \& Mantovani, R. The H2A/H2B-like histone-fold domain proteins at the crossroad between chromatin and different DNA metabolisms. Transcription 4, 114-119 (2013).

82. Mimitou, E. P., Yamada, S. \& Keeney, S. A global view of meiotic doublestrand break end resection. Science 355, 40-45 (2017).

83. Hada, A. et al. Histone octamer structure is altered early in ISW2 ATPdependent nucleosome remodeling. Cell Rep. 28, 282-294.e6 (2019).

84. Sinha, K. K., Gross, J. D. \& Narlikar, G. J. Distortion of histone octamer core promotes nucleosome mobilization by a chromatin remodeler. Science 355, eaaa3761 (2017).

85. Zofall, M., Persinger, J., Kassabov, S. R. \& Bartholomew, B. Chromatin remodeling by ISW2 and SWI/SNF requires DNA translocation inside the nucleosome. Nat. Struct. Mol. Biol. 13, 339-346 (2006)

86. Lacoste, N., Utley, R. T., Hunter, J. M., Poirier, G. G. \& Côte, J. Disruptor of telomeric silencing-1 is a chromatin-specific histone $\mathrm{H} 3$ methyltransferase. J. Biol. Chem. 277, 30421-33044 (2002).

87. Casari, E., Gobbini, E., Clerici, M. \& Longhese, M. P. Resection of a DNA double-strand break by alkaline gel electrophoresis and southern blotting. Methods Mol. Biol. 2153, 33-45 (2021).
88. Mangiagalli, M. et al. The activity and stability of a cold-active acylaminoacyl peptidase rely on its dimerization by domain swapping. Int. J. Biol. Macromol. 181, 263-274 (2021).

89. Studier, F. W. Protein production by auto-induction in high-density shaking cultures. Protein Expr. Purif. 41, 207-234 (2005).

90. Yang, J. \& Zhang, Y. I-TASSER server: new development for protein structure and function predictions. Nucleic Acids Res. 43, W174-W181 (2015).

91. Goddard, T. D. et al. UCSF ChimeraX: meeting modern challenges in visualization and analysis. Protein Sci. 27, 14-25 (2018).

\section{Acknowledgements}

We thank J. Haber, J. Diffley, and B. Pfander for providing yeast strains. We also thank G. Lucchini for the critical reading of the manuscript, and M. Villa, F. Esposito, and S. Calabrese for preliminary data. This work was supported by Fondazione AIRC under IG 2017 - ID. 19783 and Progetti di Ricerca di Interesse Nazionale (PRIN) 2017 to M.P.L. E. C. was supported by the Italian Ministry of University and Research (MIUR) through the grant "Dipartimenti di Eccellenza 2017" to the University of Milano Bicocca.

\section{Author contributions}

M.P.L. and M.C. conceived the idea. E.C. performed drop tests in Figs. 1, 4, and 7e, f; DSB resection and the relative analysis in Figs. 2a, b, 6c, d, 7a, Supplementary Fig. 4; ChIP analysis and western blot in Figs. 2c-e, 3a-d, 5, 6a, b, e, f, 7d, g, h, 8c, d, and Supplementary Fig. 3; EMSA assay in Fig. 8e, f. Coimmunoprecipitation in Supplementary Fig. 5. M.G. performed drop tests in Supplementary Fig. 2; western blot analysis in Fig. 7b, c; contributed to perform EMSA in Fig. 8e, f; E.G. performed the screen and identified the $d p b 4-A 62 S$ allele. M.M. expressed and purified Dpb3-Dpb4 and Dls1-Dpb4 heterodimers in Supplementary Fig. 6; constructed Fig. 8a, b. M.P.L. and M. C. supervised and coordinated the work. M.P.L wrote the paper. M.P.L., E.C., M.G., and M.C. revised the text.

\section{Competing interests}

The authors declare no competing interests.

\section{Additional information}

Supplementary information The online version contains supplementary material available at https://doi.org/10.1038/s41467-021-25090-9.

Correspondence and requests for materials should be addressed to M.P.L.

Peer review information Nature Communications thanks Zhiguo Zhang and the other, anonymous, reviewer(s) for their contribution to the peer review of this work. Peer reviewer reports are available.

Reprints and permission information is available at http://www.nature.com/reprints

Publisher's note Springer Nature remains neutral with regard to jurisdictional claims in published maps and institutional affiliations.

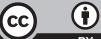

Open Access This article is licensed under a Creative Commons Attribution 4.0 International License, which permits use, sharing adaptation, distribution and reproduction in any medium or format, as long as you give appropriate credit to the original author(s) and the source, provide a link to the Creative Commons license, and indicate if changes were made. The images or other third party material in this article are included in the article's Creative Commons license, unless indicated otherwise in a credit line to the material. If material is not included in the article's Creative Commons license and your intended use is not permitted by statutory regulation or exceeds the permitted use, you will need to obtain permission directly from the copyright holder. To view a copy of this license, visit http://creativecommons.org/ licenses/by/4.0/.

(c) The Author(s) 2021 